\title{
Estimation of liquefaction potential in Eco-Delta City (Busan) using different approaches with effect of fines content
}

\author{
Bahareh Bahari', Woongki Hwang ${ }^{1}$, Tae-Hyung Kim ${ }^{1 *}$ (1) and Young-Suk Song ${ }^{2}$
}

*Correspondence:
kth67399@kmou.ac.kr
'Department of Civil
and Environmental
Engineering, Korea Maritime
and Ocean University, 727
Taejong-ro, Youngdo-Gu,
Busan 49112, Republic
of Korea
Full list of author information
is available at the end of the
article

*Correspondence: kth67399@kmou.ac.kr

Department of Civi and Ocean University, 727 Taejong-ro, Youngdo-Gu

Full list of author information article

\begin{abstract}
Soil liquefaction which is a disastrous phenomenon induced by the earthquake, is widely investigated in many researches in geotechnical engineering. In this study, a SPT-N based investigation is carried out to assess the susceptibility of liquefaction in Eco-Delta city, located in the southwestern part of Busan city in South Korea. Data from 229 sites are analyzed for the earthquake of 7.5 magnitude with a peak horizontal acceleration of $0.2 \mathrm{~g}$ to carry out the liquefaction potential index (LPI) through two deterministic methods which have different factors of safety (FS). The liquefaction probability is investigated by the deterministic and reliability methods and the liquefaction hazard maps are generated. To observe the effect of fines content and plasticity index on the liquefaction susceptibility, three different cases are considered. It is found that among the four approaches used, Overseas Coastal Area Development Institute of Japan (OCDI) method showed more sensitivity to changes of fines content and plasticity index. The Eco-Delta city is found to be highly vulnerable to liquefaction having $91 \%$ of sites with LPI values greater than 15.
\end{abstract}

Keywords: Liquefaction, Fines content, Liquefaction potential index, Liquefaction hazard map, Standard penetration test, Busan city

\section{Introduction}

Soil liquefaction refers to a phenomenon wherein a saturated soil loses strength in response to a dynamic load, usually earthquake shaking causing to increase in pore water pressure. Increase in pore water pressures is the result of rapid loading situation during seismic events where there is not enough time for dissipation of excess pore water pressures through natural drainage. The increased pore water pressure transforms granular materials from a solid to a liquefied state. Soil liquefaction mostly occurs for saturated loose sand [1]. Such a ground failures have been widely occurred during numerous devastating earthquakes and therefore, it has become an attractive research topic in geotechnical engineering. The soil liquefaction mostly depends on the magnitude of earthquake, ground motion, site specific conditions, ground acceleration, type and thickness of the soil deposit, relative density, grain size distribution, fines content, 
plasticity index of fines, degree of saturation, permeability of soil layer, ground water table and reduction of effective stress [2, 3].

Various procedures available in the literature for assessing the liquefaction phenomenon have been classified into two categories: deterministic and reliability approaches. Most of them deal with the factor of safety against liquefaction which result the potential for liquefaction to occur at certain depth for a site. The factor of safety (FS) against liquefaction is known as the ratio of the soil capacity to resist liquefaction to the applied seismic load which was proposed by Seed and Idriss [1]. The capacity to resist liquefaction is defined as the cyclic resistance ratio (CRR) and seismic load is defined as the cyclic stress ratio (CSR). There are several in situ tests which can be used for calculation of the FS of a soil layer such as standard penetration test (SPT), conic penetration test (CPT), becker penetration test (BPT) and shear wave velocity $\left(\mathrm{V}_{\mathrm{s}}\right)$ test [3]. Among them, SPT-N based simplified procedure which was proposed by Seed and Idriss [1] is widely used to calculate the liquefaction resistance of soils and is known as a deterministic approach. Using the surface level peak ground acceleration (PGA), earthquake magnitude $\left(M_{w}\right)$, and SPT N-data, namely SPT blow counts $(\mathrm{N})$, effective overburden pressure $\left(\sigma_{v}^{\prime}\right)$, fines content (FC), liquid limits and grain size distribution; FS along the depth of soil profile can be calculated $[3,4]$. To classify a soil layer using FS as liquefiable or non-liquefiable, Seed and Idriss [1] defined the soil with FS $<1$ as liquefiable and with FS $>1$ as non-liquefiable.

FS shows the liquefaction potential of a soil layer at the particular depth in the subsurface. However, it cannot show the degree of liquefaction severity. That is why Iwasaki et al. [5] proposed liquefaction potential index (LPI) to assess the degree of liquefaction severity. LPI is the integration of liquefaction potential over the depth of a soil profile and estimates the response of the soil column instead of a single soil layer at particular depth and is therefore used for liquefaction hazard maps. LPI is proportional to the depth, thickness and factor of safety against liquefaction of soil layers. Iwasaki et al. [6] showed that liquefaction effects are moderate for $5<L P I<15$ and major for LPI $>15$. Sonmez [7] identified the sites based on the LPI of the soil column as LPI $=0$ that means not likely to liquefy and $0<L P I \leq 15,2<L P I \leq 5,5<L P I \leq 15$ and LPI $>15$ as having low, moderate, high and very high liquefaction susceptibility, respectively. Seismic design specification for highway bridges of Japan [8] is the other deterministic approach that proposed procedures to assess the liquefaction potential in a site. This method defines the CRR in different term and accordingly, the FS and LPI can be calculated. The Overseas Coastal Area Development Institute of Japan [9] assessed the liquefaction possibility based on the standard penetration test $\mathrm{N}$-value and equivalent acceleration which is a deterministic approach. Based on this method, the liquefaction possibility for a site would be in four levels; very low, low, high and very high. The liquefaction probability considering parameter uncertainties can be investigated as reliability approach. Some logarithmic regression analyses of field performance data have been conducted to derive empirical equations to interpret the probability of liquefaction [1012]. Some models have also been proposed according to the artificial neural network by Juang et al. [13] and Bayesian mapping functions by Cetin et al. [14]. Jha and Suzuki [15] proposed a model based on the standard normal cumulative probability $\Phi($.$) which is$ the function of reliability index $\beta^{\prime}$. Reliability analysis provide a means of evaluating the 
effects of uncertainties and provide a framework for choosing factors of safety which are appropriate for the degree of uncertainty.

This study attempts to assess the susceptibility of liquefaction in Eco-Delta city in Busan through three deterministic approaches which are Seed and Idriss [1] approach, seismic design specification for highway bridges of Japan [8] approach, overseas coastal area development institute of Japan [9] approach; and one reliability approach which is Jha and Suzuki [15] approach. Especially, the study presents the sensitivity of each method in evaluation of liquefaction probability considering three cases of fines content and plasticity index.

\section{Investigation of study area}

\section{Geological and tectonic}

Busan metropolitan city is located in southeastern part of South Korea as shown in Fig. 1. It covers an area of about $770 \mathrm{~km}^{2}$ having the population of about 3.5 million being the second largest city in South Korea. The city is surrounded by the Ulsan metropolitan city in the north, the Gyeongsangnam-do province in the west and East Sea in the east and south. The city is $400 \sim 800 \mathrm{~m}$ above the sea level.

The Sineo mountain located in Gimhae, which reaches Yeondae in Gadeok island, surrounds the western part of the city. In the east, there are Geumjeong and Baegyang mountains. These mountains do not show continuity of mountain ranges due to the erosive action of rivers. The main rivers in the city are Nakdong, Suyeong, Oncheon and Dongcheon, which are shown in Fig. 2 [16]. Busan city is the cretaceous Yangsan basin, which is the largest basin in South Korea. It is divided into the small basins, the sedimentary rocks of the Shindong formation, the Hayang

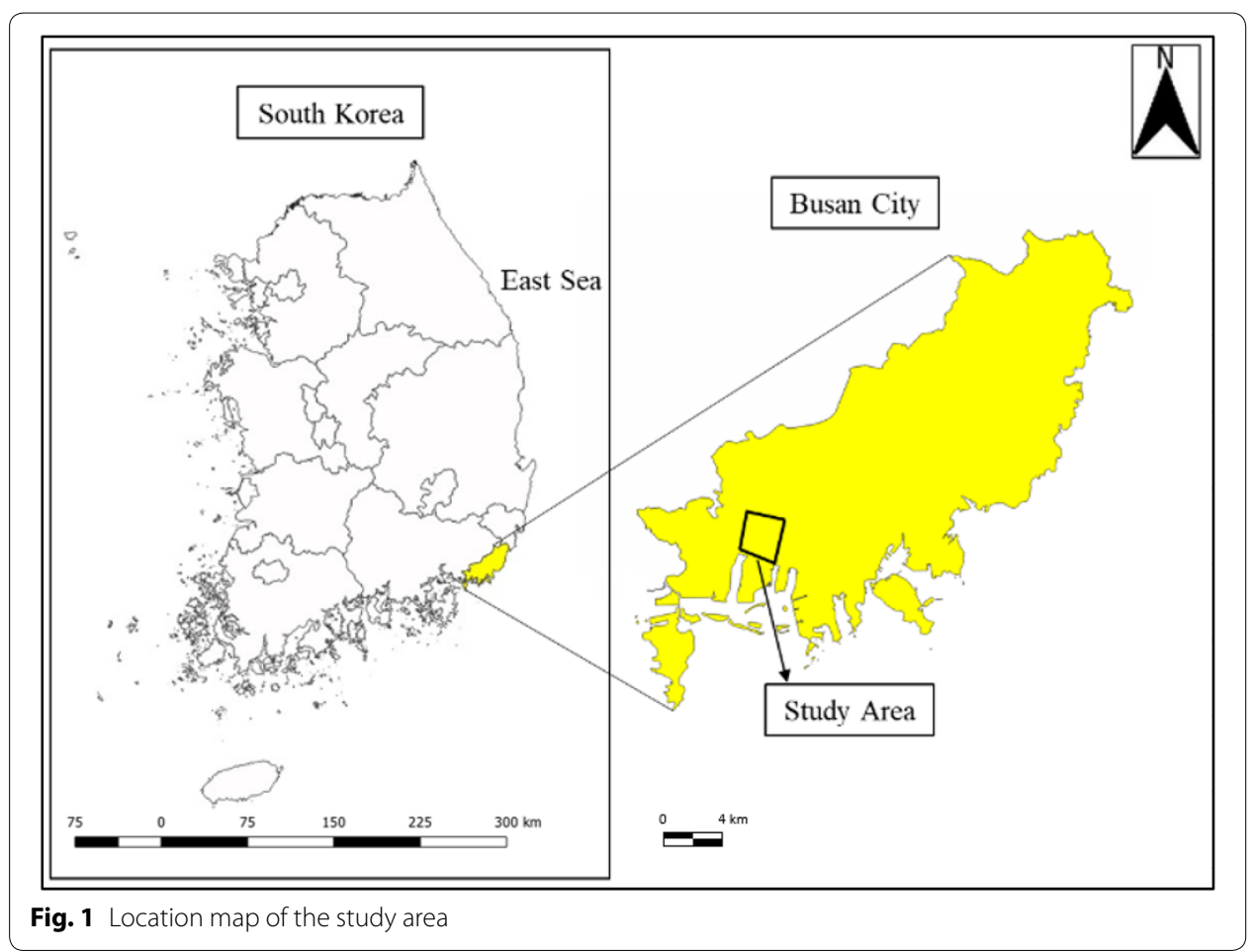




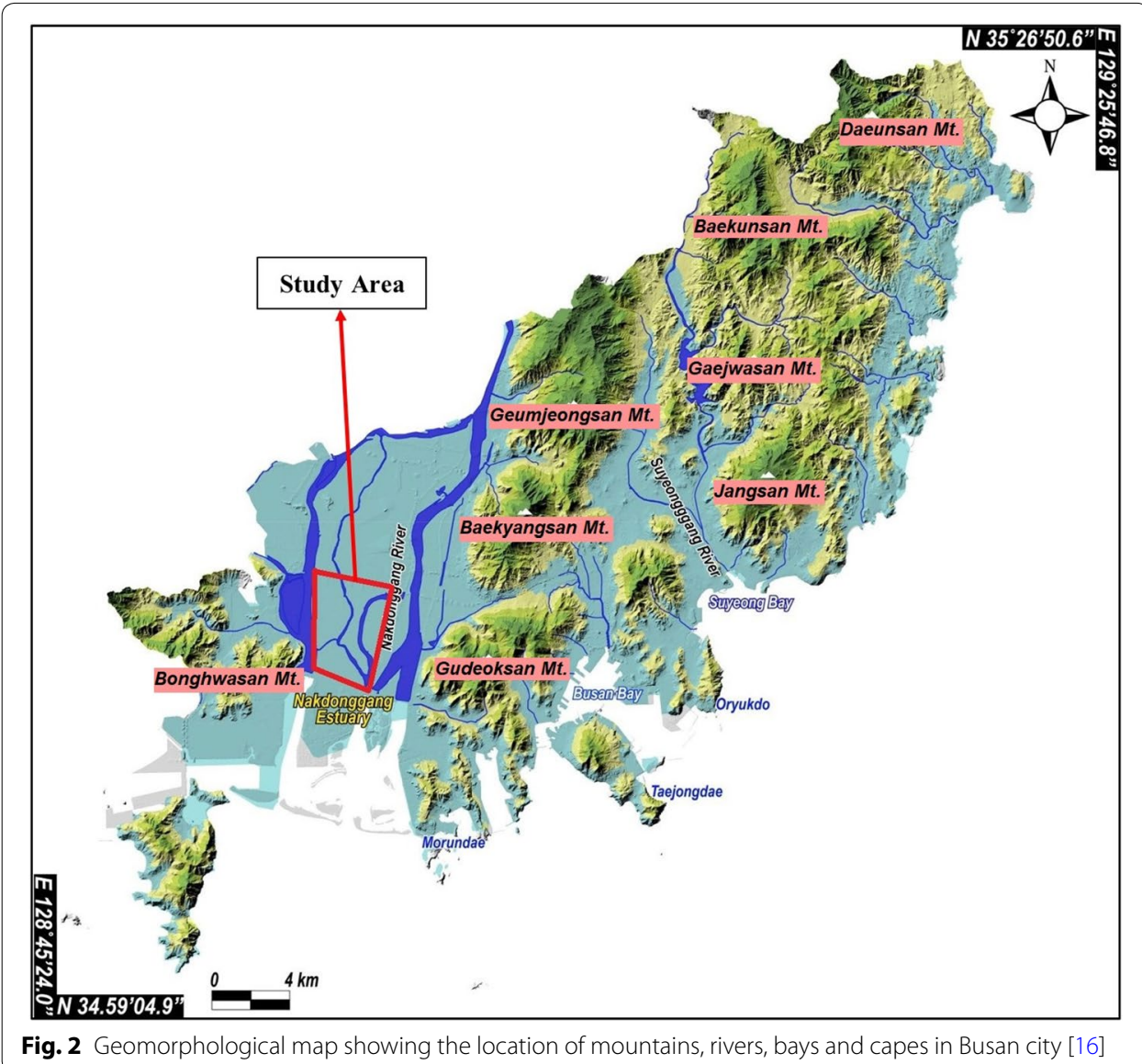

formation, and the Bulguksa granite formation. The city is covered by the Miryang small basin dominated by volcanic rocks and Icheonri layer deposited between these volcanic rocks. Taejongdae layer, Dadaepo layer and Jeonggak layer composed of acidic volcanic rocks based on rhyolite Bulguksa granitoids acidic and neutrophilic dykes and rocks, which are surrounded by the lateral layer and the quaternary alluvial deposits.

\section{Seismotectonics}

The seismic structure of the city consists of the Korean peninsula which is the largest structure line of the Yangsan fault system extending from north to the northeast direction, the Dongnae fault which passes through the downtown of Busan city, and the small fault of Ilgwang fault [17]. The geological map of the city and distribution of major fault is shown in Fig. 3.

Recently South Korea has experienced two earthquakes near the Busan city which are the Gyeonju earthquake in 2016 having the magnitude of 5.8 and the Pohang earthquake in 2017 having the magnitude of 5.4. In order to investigate the critical condition in liquefaction analysis, the earthquake with magnitude of 7.0 in considered in this study. 


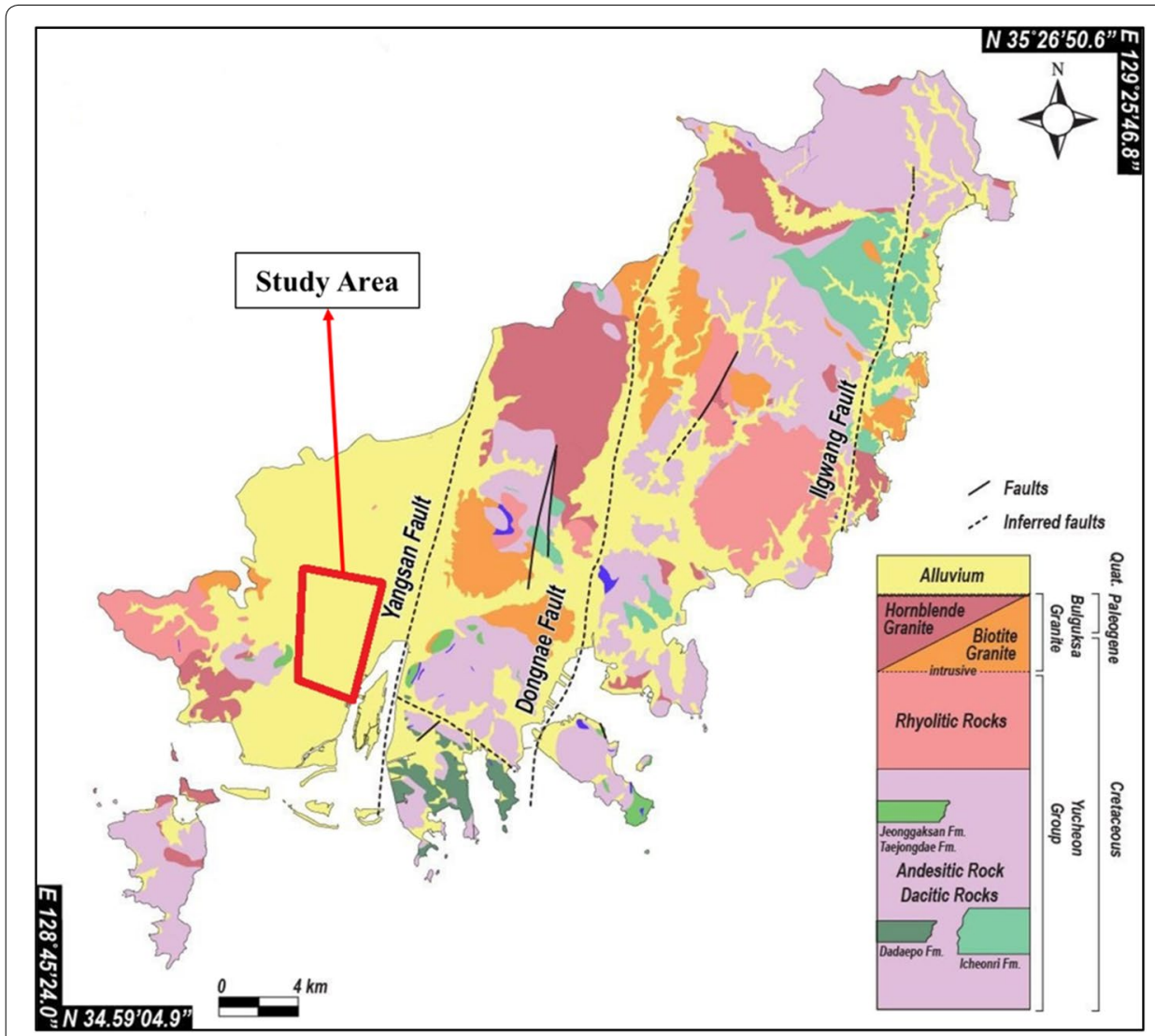

Fig. 3 Geological map of the Busan showing the distribution of basin-fills and major faults [16]

\section{Study area}

The study area is the Eco-Delta city having the area of $11.77 \mathrm{~km}^{2}$, which is located in the southwestern part of the Busan city. As is shown in Fig. 3, the soil of this area is all alluvial deposit. The deposit consists of loose sand (upper sand), thick soft clay (upper clay), sand (lower sand), soft clay (lower clay) and sand and gravel layers on bedrocks that sometimes reaches over $50-60 \mathrm{~m}$ in thickness. Geological investigations imply that the sand layers cover from the ground surface to the depth of about $8 \mathrm{~m}$ in most of the Eco-Delta city and the clay or silt cover over the depth of $12 \mathrm{~m}$.

The range of ground water table (GWT) for the sites is from zero to $2.5 \mathrm{~m}$ below the ground surface, which is shown as a contour map in Fig. 4. The Eco-Delta city is divided to three parts named as part 1, 2 and 3 which are shown in Fig. 5a. The results of in situ geotechnical tests are collected for total 229 boreholes including 83 boreholes in part 1,110 boreholes in part 2 and 36 boreholes in part 3 . One typical borehole is selected in part 1 to show the further results named as borehole B-25. The location of 229 boreholes and aforementioned typical borehole (encircled) are also plotted in Fig. 5a. The typical representative soil profile is shown in Fig. 5b. 


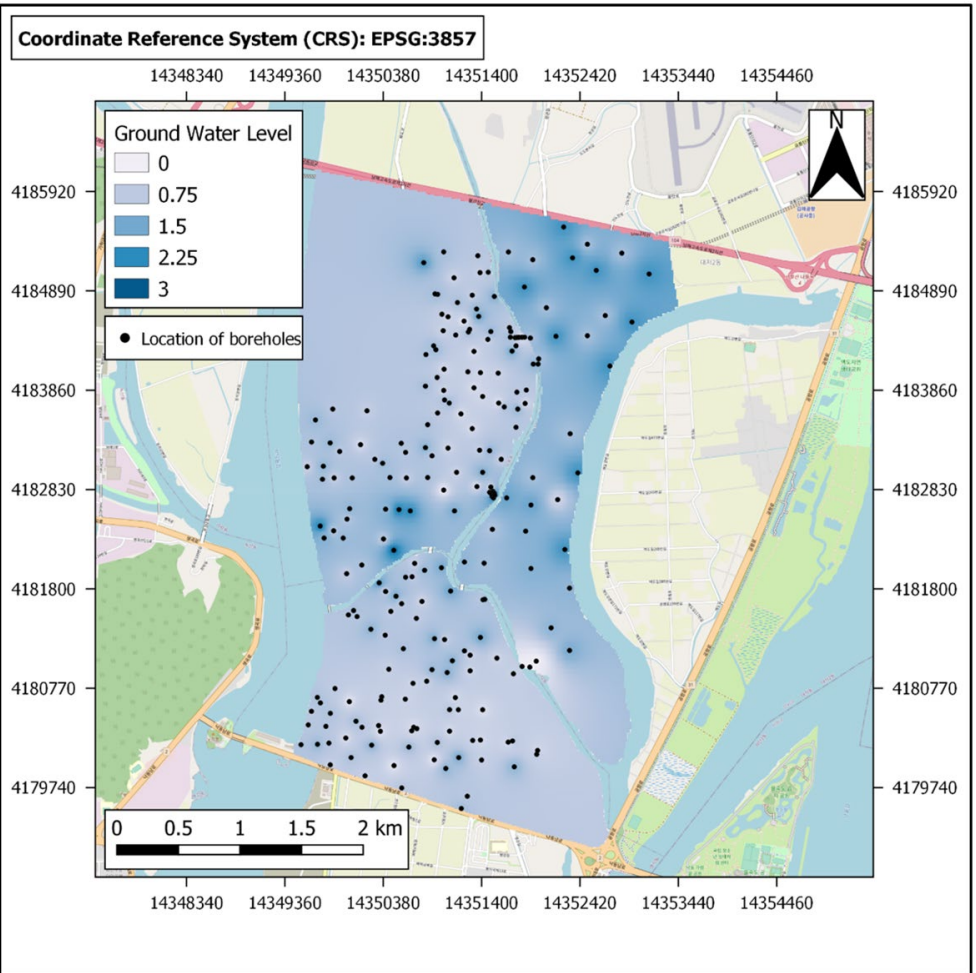

Fig. 4 Distribution of GWT in the study area

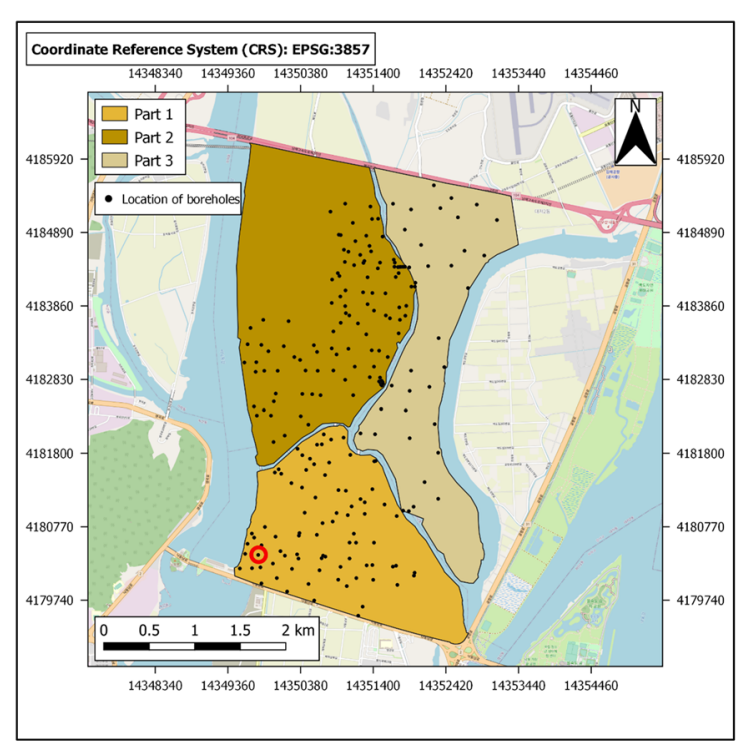

a

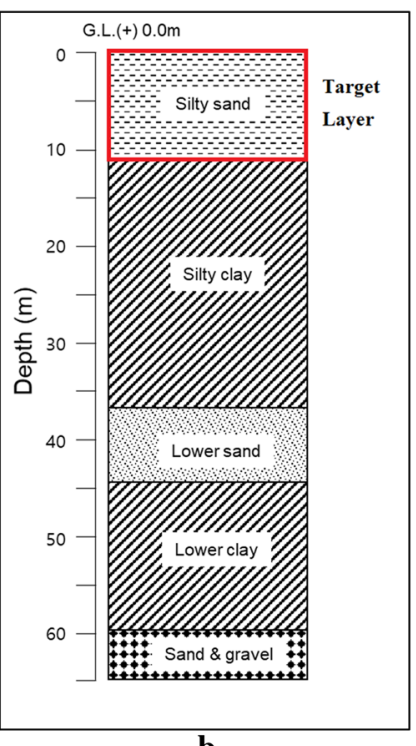

b

Fig. 5 a The location of boreholes, and $\mathbf{b}$ Typical representative soil profile

In addition, the standard penetration test $\mathrm{N}$-values from in situ data of sand layer are categorized into five categories based on the proposed range by Terzaghi et al. 


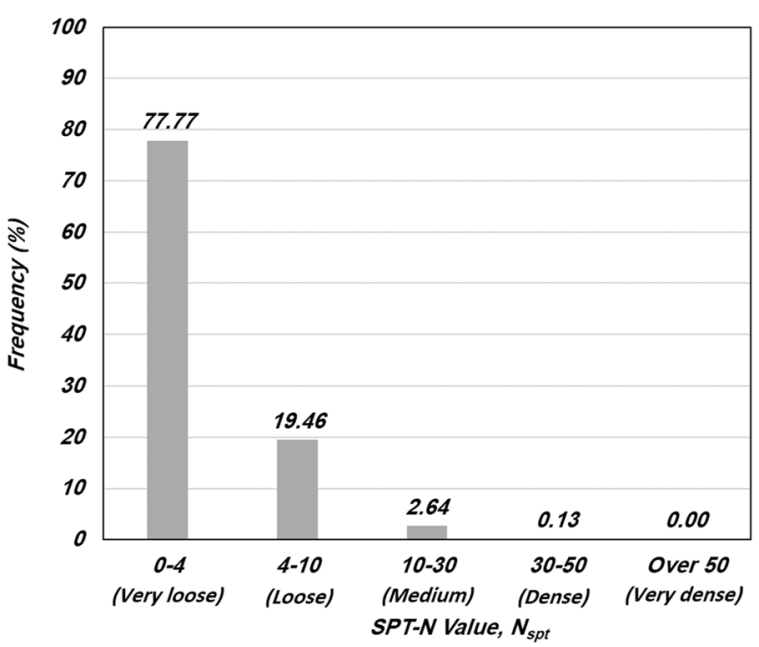

Fig. 6 Histogram of 4543 in situ SPT N-value records of sand layer

[18] and the histogram of them is shown in Fig. 6 . This figure shows that over $75 \%$ of the soil layers in this area are lied in the range of very loose.

\section{Deterministic evaluation of liquefaction probability}

Regarding the sensitivity of the area due to having the loose silty sand soil, the evaluation of the liquefaction susceptibility through different methods is reasonable rather than using only one method. Therefore, the liquefaction susceptibility is carried out through four approaches consisting of Seed and Idriss [1] approach, Seismic Design Specification for Highway Bridges of Japan [8] approach (hereafter called as DSHB), Overseas Coastal Area Development Institute of Japan [9] approach (hereafter called as OCDI) and Jha and Suzuki [15] approach. The process of each approach is explained in the following section.

\section{Seed and Idriss approach}

Based on the simplified procedure that was proposed by Seed and Idriss [1], FS can be expressed by comparison of the cyclic stress ratio (CSR) with the cyclic resistance ratio (CRR). The equation for calculation of FS can be defined as Eq. (1):

$$
F S=\frac{C R R_{7.5}}{C S R} M S F
$$

where CSR is the calculated cyclic stress ratio generated by the earthquake; and CRR 7.5 is the cyclic resistance ratio for the earthquake of 7.5 magnitude. The term MSF which was defined by Seed and Idriss [19], is the magnitude scaling factor and it must be used when the earthquake magnitude is not equal to 7.5. Since this study considers the magnitude of earthquake of 7.5 Richter, the MSF is considered as 1.

The cyclic stress ratio can be defined as Eq. (2):

$$
\operatorname{CSR}=\frac{\tau_{a v}}{\sigma_{v o}^{\prime}}=0.65\left(\frac{a_{\max }}{g}\right)\left(\frac{\sigma_{v o}}{\sigma_{v o}^{\prime}}\right) r_{d}
$$


where $a_{\max }$ is the peak horizontal ground acceleration induced by the earthquake shaking at the ground surface; $g$ is the gravity acceleration; $\sigma_{v o}$ and $\sigma_{v o}^{\prime}$ are the total and effective vertical overburden stress, respectively, at the particular depth below the ground surface; and $r_{d}$ is the stress reduction factor which depends to the depth.

In order to determine the $\mathrm{a}_{\max }$ in the study area, the result of Park et al. [20] research is used. They investigated the distribution of horizontal peak ground acceleration (PGA) during the Gyeonju earthquake in 2016 and determined that the horizontal peak ground acceleration is about $0.2 \mathrm{~g}$ in Busan province.

The $r_{d}$ values against the soil depth was plotted by Seed and Idriss [1]. However, for ease of computation, Youd et al. [3] approximated the mean curve plotted in Seed and Idriss by Eq. (3):

$$
r_{d}=\frac{\left(1.000-0.4113 z^{0.5}+0.04052 z+0.001753 z^{1.5}\right)}{\left(1.000-0.4177 z^{0.5}+0.05729 z^{1.5}+0.001210 z^{2}\right)}
$$

where $\mathrm{z}$ is the depth below the ground surface in meters.

Regarding the influence of fines content on CRR, the calculated $\left(\mathrm{N}_{1}\right)_{60}$ requires considering fines content $(\mathrm{FC})$ of the soil to which leads to equivalent clean sand value $\left(\mathrm{N}_{1}\right)_{60 \mathrm{cs}}$. Youd et al. [3] developed Eq. (4) for equivalent clean sand value, $\left(\mathrm{N}_{1}\right)_{60 \mathrm{cs}}$ :

$$
\left(N_{1}\right)_{60 c s}=\alpha+\beta\left(N_{1}\right)_{60}
$$

where $\alpha$ and $\beta$ are coefficients determined from the Eqs. (5) and (6), respectively:

$$
\begin{gathered}
\left\{\begin{array}{c}
\alpha=0 \text { for } F C \leq 5 \% \\
\alpha=\exp \left[1.76-\left(190 / F C^{2}\right)\right] \\
\alpha=5.0 \text { for } F C \geq 35 \%
\end{array} \text { for } 5 \%<F C<35 \%\right. \\
\left\{\begin{array}{c}
\beta=1 \text { for } F C \leq 5 \% \\
\beta=\exp \left[0.99-\left(F C^{1.5} / 1000\right)\right] \\
\beta=1.2 \text { for } F C \geq 35 \%
\end{array} \text { for } 5 \%<F C<35 \%\right.
\end{gathered}
$$

In order to further investigate the effect of fines content to the liquefaction, three different cases are considered for the percent of fines content and plasticity index for each borehole, which are tabulated in Table 1.

The soil specifications and calculated cyclic stress ratio for borehole B-25 is shown in Table 2.

The value of cyclic resistance ratio proposed by Youd et al. [3] is expressed as Eq. (7):

Table 1 Considered cases for fines content and plasticity index

\begin{tabular}{lll}
\hline Case type & Percent of fines content & Plasticity index \\
\hline Case 1 & $\mathrm{FC}=5 \%$ & $\mathrm{Pl}=5 \%$ \\
Case 2 & $\mathrm{FC}=15 \%$ & $\mathrm{Pl}=10 \%$ \\
Case 3 & $\mathrm{FC}=35 \%$ & $\mathrm{Pl}=20 \%$ \\
\hline
\end{tabular}


Table 2 Soil characteristics of borehole B-25

\begin{tabular}{|c|c|c|c|c|c|c|c|c|c|c|c|c|c|}
\hline \multicolumn{14}{|l|}{$G W L=0.85 m$} \\
\hline Depth $(m)$ & 1.5 & 3.0 & 4.5 & 6.0 & 7.5 & 9.0 & 10.5 & 12.0 & 13.5 & 15.0 & 16.5 & 18.0 & 19.5 \\
\hline USCS & $C L$ & SM & SM & SM & SM & SM & SM & SM & $M L$ & $M L$ & $M L$ & $M L$ & $\mathrm{CL}$ \\
\hline SPT-N & 2 & 2 & 3 & 5 & 4 & 4 & 4 & 3 & 2 & 2 & 1 & 3 & 0 \\
\hline$\gamma\left(k N / m^{3}\right)$ & 16.2 & 16.2 & 16.3 & 16.5 & 16.4 & 16.4 & 16.4 & 16.3 & 16.2 & 16.2 & 16.1 & 16.3 & 16.0 \\
\hline$\sigma_{v}^{\prime}\left(k N / m^{2}\right)$ & 17.92 & 27.51 & 37.24 & 47.28 & 57.16 & 67.05 & 76.93 & 86.67 & 96.25 & 105.8 & 115.3 & 125.0 & 134.3 \\
\hline CSR & - & 0.225 & 0.247 & 0.258 & 0.263 & 0.263 & 0.259 & 0.252 & - & - & - & - & - \\
\hline
\end{tabular}

$$
C R R_{7.5}=\frac{1}{34-\left(N_{1}\right)_{60 c s}}+\frac{\left(N_{1}\right)_{60 c s}}{35}+\frac{50}{\left[10\left(N_{1}\right)_{60 c s}+45\right]^{2}}-\frac{1}{200}
$$

The values of $\mathrm{CRR}_{7.5}$ are calculated for all sites in order to calculate the FS of each borehole by Eq. (1).

LPI is a single-valued parameter to assess liquefaction potential. It is calculated by integrating the FS along the soil column up to $20 \mathrm{~m}$ depth at a site. There is a weighting function used in LPI to have more weight to the layers closer to the ground surface. The LPI proposed by Iwasaki et al. [5, 6] is expressed as Eq. (8):

$$
L P I=\int_{0}^{20} F(z) \cdot w(z) d z
$$

where $\mathrm{z}$ is depth at the midpoint of the soil layer and varies from 0 to $20 \mathrm{~m}$. The weighting factor, $\mathrm{w}(\mathrm{z})$, and the severity factor, $\mathrm{F}(\mathrm{z})$, are calculated as Eqs. (9) and (10), respectively:

$$
\begin{aligned}
& \left\{\begin{array}{l}
F(z)=1-F S \text { for } F S<1.0 \\
F(z)=0 \text { for } F S \geq 1.0
\end{array}\right. \\
& \left\{\begin{array}{l}
w(z)=10-0.5 z \text { for } z<20 m \\
w(z)=0 \text { for } z>20 m
\end{array}\right.
\end{aligned}
$$

All the sites data have been analyzed based on the Seed and Idriss [19] method to calculate the FS and recognize the liquefiable and non-liquefiable segments as well, where liquefaction is predicted to occur if $\mathrm{FS}<1$ and no liquefaction is predicted to occur if FS $>1$. Then the liquefaction potential index is evaluated. The calculations of safety factors against liquefaction for the earthquake of 7.5 magnitude and the liquefaction potential index for three cases is listed in Table 3 for borehole B-25.

\section{DSHB [8] approach}

In order to evaluate the FS through the seismic design specification for highway bridges of Japan [8] approach, the CRR should be evaluated as Eq. (11):

$$
C R R=c_{w} R_{L}
$$


Table 3 Calculation details of LPI through Seed and Idriss [1] method for borehole B-25

\begin{tabular}{|c|c|c|c|c|c|c|c|c|c|c|c|c|c|}
\hline Depth $(m)$ & 1.5 & 3.0 & 4.5 & 6.0 & 7.5 & 9.0 & 10.5 & 12.0 & 13.5 & 15.0 & 16.5 & 18.0 & 19.5 \\
\hline \multicolumn{14}{|c|}{ Case 1: $F C=5 \%, P I=5 \%$} \\
\hline$\left(N_{1}\right)_{60 c s}$ & 3.400 & 3.400 & 4.916 & 7.271 & 5.291 & 4.885 & 4.560 & 3.222 & 2.038 & 1.944 & 0.931 & 2.683 & 0 \\
\hline$C R R_{7.5}$ & 0.061 & 0.061 & 0.071 & 0.090 & 0.074 & 0.071 & 0.069 & 0.060 & 0.053 & 0.052 & 0.048 & 0.054 & 0.046 \\
\hline FS & - & 0.271 & 0.289 & 0.349 & 0.283 & 0.271 & 0.265 & 0.237 & - & - & - & - & - \\
\hline \multicolumn{14}{|c|}{$L P I=46.95$} \\
\hline \multicolumn{14}{|c|}{ Case 2: $F C=15 \%, P l=10 \%$} \\
\hline$\left(N_{1}\right)_{60 c s}$ & 6.062 & 6.062 & 7.650 & 10.12 & 8.043 & 7.618 & 7.278 & 5.876 & 4.635 & 4.536 & 3.474 & 5.310 & 2.498 \\
\hline$C R R_{7.5}$ & 0.080 & 0.080 & 0.093 & 0.114 & 0.096 & 0.093 & 0.090 & 0.079 & 0.069 & 0.068 & 0.060 & 0.071 & 0.052 \\
\hline FS & - & 0.356 & 0.376 & 0.443 & 0.367 & 0.353 & 0.347 & 0.313 & - & - & - & - & - \\
\hline \multicolumn{14}{|c|}{$L P I=41.36$} \\
\hline \multicolumn{14}{|c|}{ Case $3: F C=35 \%, P I=20 \%$} \\
\hline$\left(N_{1}\right)_{60 c s}$ & 9.08 & 9.08 & 10.89 & 13.72 & 11.34 & 10.86 & 10.47 & 8.867 & 7.446 & 7.333 & 6.118 & 8.220 & 5.000 \\
\hline$C R R_{7.5}$ & 0.105 & 0.105 & 0.121 & 0.148 & 0.125 & 0.121 & 0.117 & 0.103 & 0.091 & 0.089 & 0.078 & 0.093 & 0.068 \\
\hline FS & - & 0.467 & 0.490 & 0.573 & 0.477 & 0.459 & 0.452 & 0.410 & - & - & - & - & - \\
\hline$\angle P I=34.0$ & & & & & & & & & & & & & \\
\hline
\end{tabular}

where $c_{w}$ is the modification factor on the earthquake ground motion which is 1.0 in the present study according to the condition described in this approach. $\mathrm{R}_{\mathrm{L}}$ is the cyclic triaxial shear resistance ratio which obtains from Eq. (12):

$$
R_{L}=\left\{\begin{array}{l}
0.0882 \sqrt{N_{a} / 1.7} N_{a}<14 \\
0.0882 \sqrt{N_{a} / 1.7}+\left[1.6 \times 10^{-6} \times\left(N_{a}-14\right)^{4.5}\right] N_{a} \geq 14
\end{array}\right.
$$

where $\mathrm{N}_{\mathrm{a}}$ is the modified $\mathrm{N}$-value regarding the effect of grain size that for sandy soil is calculated as Eq. (13):

$$
N_{a}=c_{1} N+c_{2}
$$

where $c_{1}$ and $c_{2}$ are the correction factors with respect to the fines content and defined as Eqs. (14) and (15), respectively:

$$
\begin{aligned}
& c_{1}=\left\{\begin{array}{c}
10 \% \leq F C<10 \% \\
\frac{F C+40}{50} 10 \% \leq F C<60 \% \\
(F C / 20)-1 F C \geq 60 \%
\end{array}\right. \\
& c_{2}=\left\{\begin{array}{l}
00 \% \leq F C<10 \% \\
\frac{F C-10}{18} F C \geq 10 \%
\end{array}\right.
\end{aligned}
$$

Similarly, 229 boreholes data are analyzed through the DSHB [8] method to calculate the FS against liquefaction and liquefaction potential index. It is noted that the factor of safety is not considered for the layers containing clay or silt. The calculation results for three cases is listed in Table 4 for borehole B-25.

Figure 7 shows the soil USCS classification profile, in situ SPT N-values and safety factor against liquefaction along the depth through Seed and Idriss [1] and DSHB [8] method for borehole B-25. It is obvious from the figure that the calculated factor of 
Table 4 Calculation details of LPI through DSHB [8] method for borehole B-25

\begin{tabular}{|c|c|c|c|c|c|c|c|c|c|c|c|c|c|}
\hline Depth $(m)$ & 1.5 & 3.0 & 4.5 & 6.0 & 7.5 & 9.0 & 10.5 & 12.0 & 13.5 & 15.0 & 16.5 & 18.0 & 19.5 \\
\hline \multicolumn{14}{|c|}{ Case 1: $F C=5 \%, P I=5 \%$} \\
\hline$N_{a}$ & 3.867 & 3.487 & 4.756 & 7.248 & 5.347 & 4.962 & 4.628 & 3.255 & 2.045 & 1.934 & 0.918 & 2.615 & 0 \\
\hline$R$ & 0.148 & 0.137 & 0.171 & 0.231 & 0.186 & 0.176 & 0.167 & 0.131 & 0.097 & 0.094 & 0.065 & 0.113 & 0 \\
\hline FS & - & 0.610 & 0.691 & 0.899 & 0.707 & 0.669 & 0.645 & 0.520 & - & - & - & - & - \\
\hline \multicolumn{14}{|c|}{$L P I=20.52$} \\
\hline \multicolumn{14}{|c|}{ Case $2: F C=15 \%, P l=10 \%$} \\
\hline$N_{a}$ & 4.531 & 4.113 & 5.509 & 8.251 & 6.160 & 5.736 & 5.369 & 3.859 & 2.527 & 2.405 & 1.287 & 3.155 & 0.278 \\
\hline$R$ & 0.165 & 0.154 & 0.190 & 0.255 & 0.206 & 0.195 & 0.186 & 0.147 & 0.110 & 0.107 & 0.077 & 0.128 & 0.036 \\
\hline FS & - & 0.685 & 0.767 & 0.989 & 0.783 & 0.742 & 0.718 & 0.585 & - & - & - & - & - \\
\hline \multicolumn{14}{|c|}{$L P I=15.51$} \\
\hline \multicolumn{14}{|c|}{ Case $3: F C=35 \%, P I=20 \%$} \\
\hline$N_{a}$ & 7.190 & 6.619 & 8.522 & 12.26 & 9.410 & 8.832 & 8.331 & 6.272 & 4.456 & 4.290 & 2.765 & 5.312 & 1.389 \\
\hline$R$ & 0.230 & 0.217 & 0.261 & 0.344 & 0.281 & 0.268 & 0.257 & 0.208 & 0.163 & 0.159 & 0.117 & 0.185 & 0.080 \\
\hline FS & - & 0.962 & 1.056 & 1.335 & 1.071 & 1.019 & 0.989 & 0.827 & - & - & - & - & - \\
\hline$L P I=1.59$ & & & & & & & & & & & & & \\
\hline
\end{tabular}

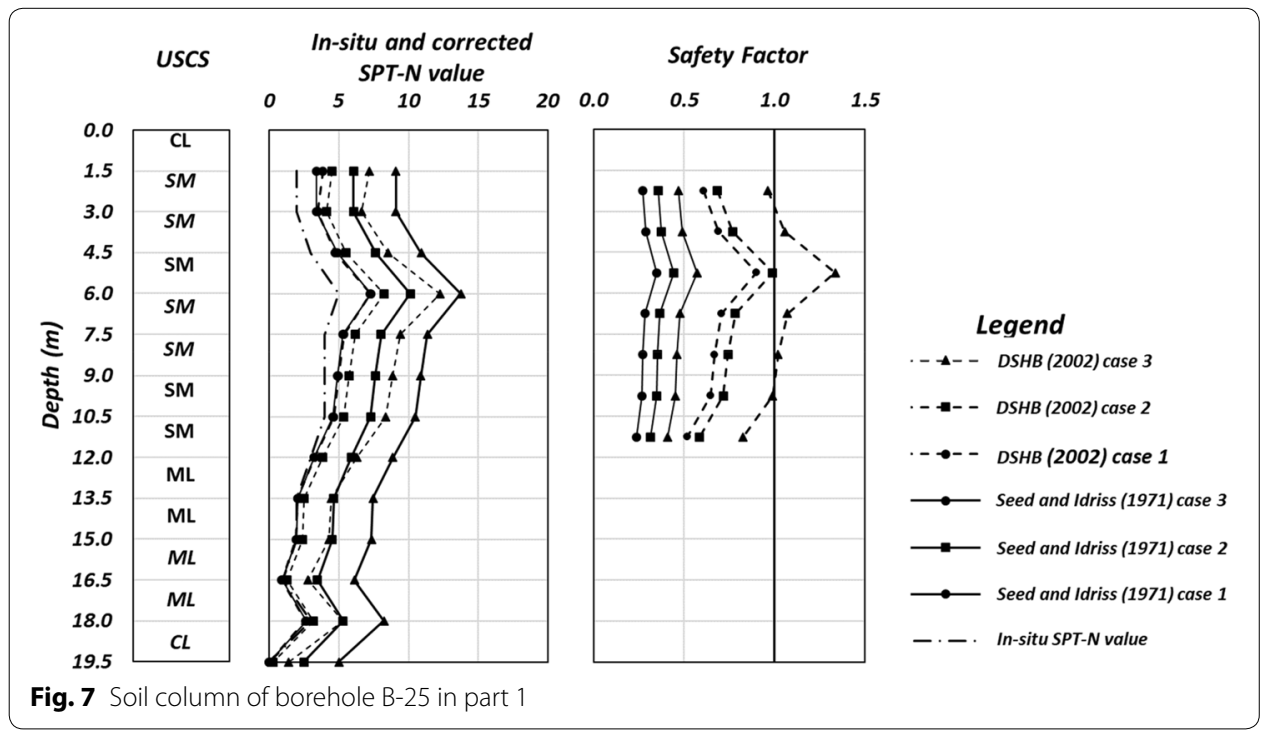

safety values are smaller for case 1 rather than case 2, and for case 2 rather than case 3 due to increase in the percent of fines content. Moreover, there is a notable difference in calculated factor of safety values through two methods, so that the obtained values by Seed and Idriss [1] method are smaller than those by DSHB [8] method in all the depths for three cases.

The comparison of the calculated factor of safety against liquefaction through Seed and Idriss [1] method and DSHB [8] method can be found in the histogram form of Fig. 8(a) for cases 1, 2 and 3. Based on this figure, when the amount of fines content is $5 \%$, the majority frequency of calculated factor of safeties lie in the range of zero 

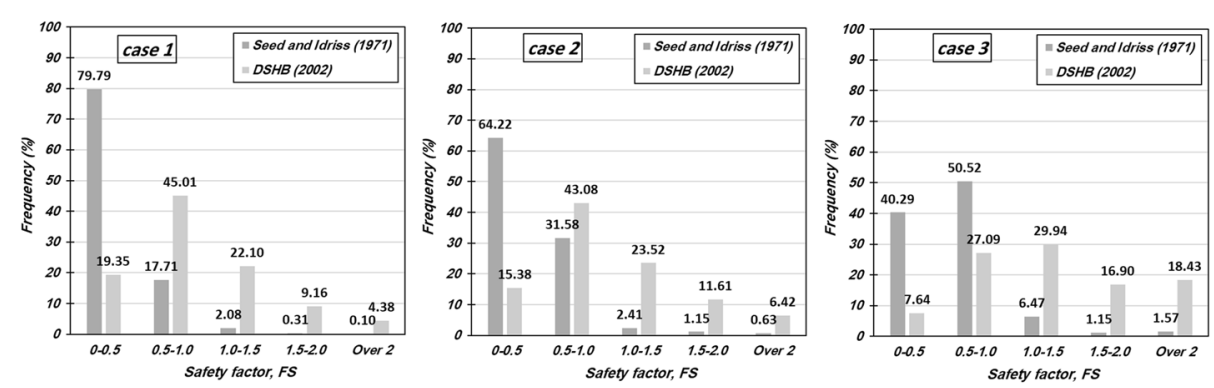

a

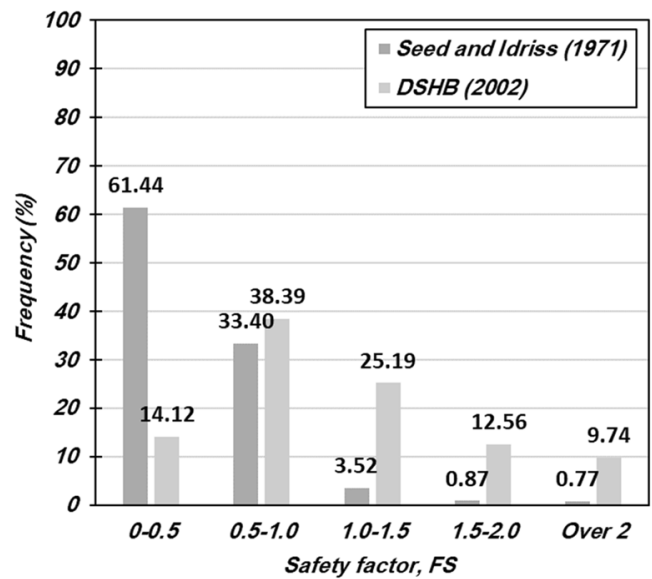

b

Fig. 8 Histogram of calculated safety factors against liquefaction through Seed and Idriss [1] and DSHB [8] method for: $\mathbf{a}$ cases 1,2 and 3 ; and $\mathbf{b}$ three cases

to 0.5 . However, when the amount of fines content increased to $35 \%$, the majority frequency of calculated factor of safeties lie in the range of 0.5 to 1.0. Figure $8 \mathrm{~b}$ shows the histogram of calculated factor of safety against liquefaction for three cases. This figure illustrates that over $60 \%$ of the soil layers have the factor of safety values less than 0.5 based on the Seed and Idriss [1] method. However, it is only about $14 \%$ based on the DSHB [8] method. The next majority of calculated safety factor values through Seed and Idriss [1] method is about $33 \%$ and lies in the range of 0.5 to 1.0 ; which is about $26 \%$ and lies in the range of 1.0 to 1.5 through DSHB [8] method. The third majority are only about $3 \%$ of soil layers which their safety factor values lie in the range of 1.0 to 1.5 through Seed and Idriss [1] method, while it is about $14 \%$ and lies in the range of 0 to 0.5 through DSHB [8] method. This figure shows that over $95 \%$ of calculated safety factor values through Seed and Idriss [1] method are less than 1.0 and only about $5 \%$ of them are greater than 1.0 and this implies the high susceptibility of the area to the liquefaction. Beside this, it is seen that calculated safety factor values through DSHB [8] method is almost normally distributed from zero to 2.0. 

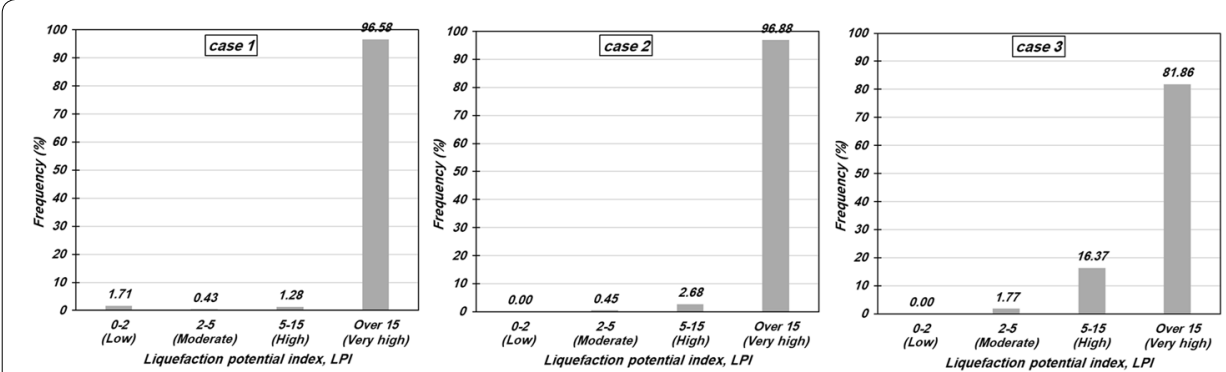

$\mathbf{a}$

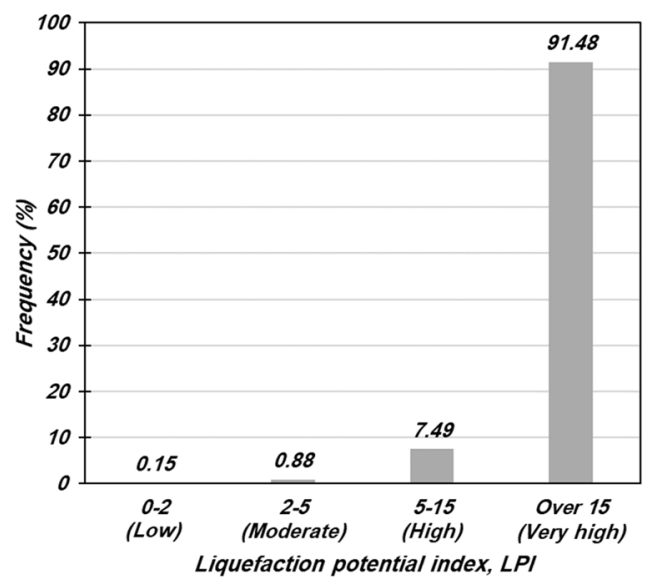

b

Fig. 9 Histogram of calculated LPI values through Seed and Idriss [1] method for: a cases 1, 2 and 3; and $\mathbf{b}$ three cases

Figure 9a shows the calculated liquefaction potential index for case 1, 2 and 3 through Seed and Idriss [1] method separately. From this figure, the effect of increasing fines content on the liquefaction potential index is visible, so that in case 1 when the amount of fines content is $5 \%$, about $96 \%$ of sites have LPI over 15 . However, in case 3 when the amount of fines content is $35 \%$, about $82 \%$ of sites have LPI over 15 and about $16 \%$ have LPI between 5 and 15. The calculated liquefaction potential index for 687 cases (229 boreholes considering three cases) through Seed and Idriss [1] method is investigated in Fig. 9b. This figure clearly shows the high vulnerably for liquefaction of the study area. About $91 \%$ of the sites show the liquefaction potential index greater than 15 and it shows very high susceptibility of the sites to liquefaction.

\section{OCDI approach}

To investigate the liquefaction severity through the Overseas Coastal Area Development Institute of Japan [9], the equivalent $\mathrm{N}$-value and equivalent acceleration of the soil layer are calculated by Eqs. (16) and (17), respectively and the soil layer should be classified according to the ranges named I-IV in Fig. 10. 


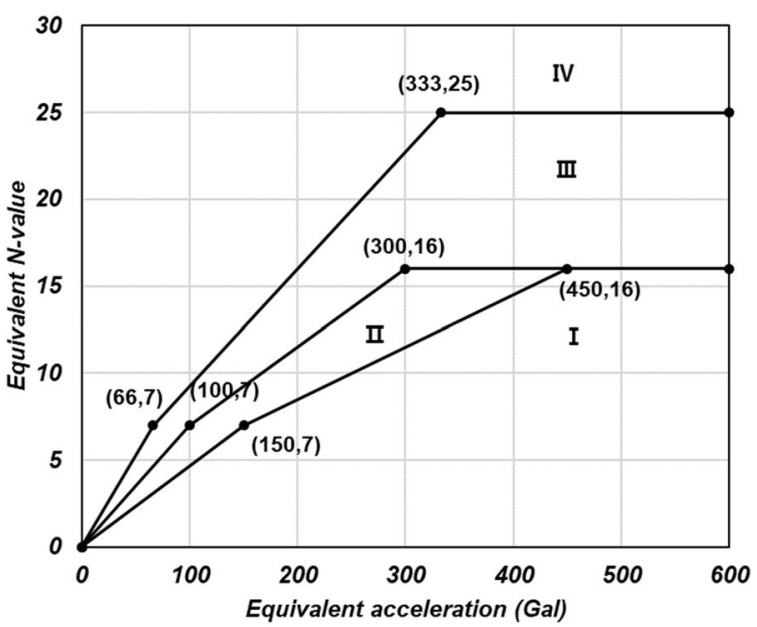

Fig. 10 Classification of Soil Layer by Equivalent N-Value and Equivalent Acceleration [9]

Table 5 Prediction of liquefaction according to OCDI [9] method

\begin{tabular}{ll}
\hline Layer range & $\begin{array}{l}\text { Prediction } \\
\text { of liquefaction }\end{array}$ \\
\hline I & Very high \\
II & High \\
IV & Low \\
\hline
\end{tabular}

$$
\begin{aligned}
& (N)_{65}=\frac{N-0.019\left(\sigma_{v}^{\prime}-65\right)}{0.0041\left(\sigma_{v}^{\prime}-65\right)+1.0} \\
& \alpha_{e q}=0.7 \times \frac{\tau_{\max }}{\sigma_{v}^{\prime}} g
\end{aligned}
$$

where $\tau_{\max }$ and $\sigma_{\mathrm{v}}^{\prime}$ are the maximum shear stress and effective overburden pressure of the subsoil in $\mathrm{kN} / \mathrm{m}^{2}$, respectively.

The description of layer range for OCDI [9] prediction is listed in Table 5.

To assess the effect of fines content, OCDI [9] proposed the correction of $\mathrm{N}$-value based on soil plasticity index when the fines content is $5 \%$ or greater through three following cases: 
Case A: If the plasticity index is less than 10 , or if the fines content is less than $15 \%$, the corrected equivalent $\mathrm{N}$-value should be set as $(N)_{65} / c_{N}$ where the $\mathrm{c}_{\mathrm{N}}$ is the compensation factor and can be obtained by Fig. 11 .

Case B: If the plasticity index lies between 10 and 20, and the fines content is $15 \%$ or higher, the corrected equivalent $\mathrm{N}$-value should be set as both $(N)_{65} / 0.5$ and $N+\Delta N$, and the range should be specified according to the following situations, where the value of $\Delta \mathrm{N}$ is given by the Eq. (18):

$$
\Delta N=8+[0.4 \times(P I-10)]
$$

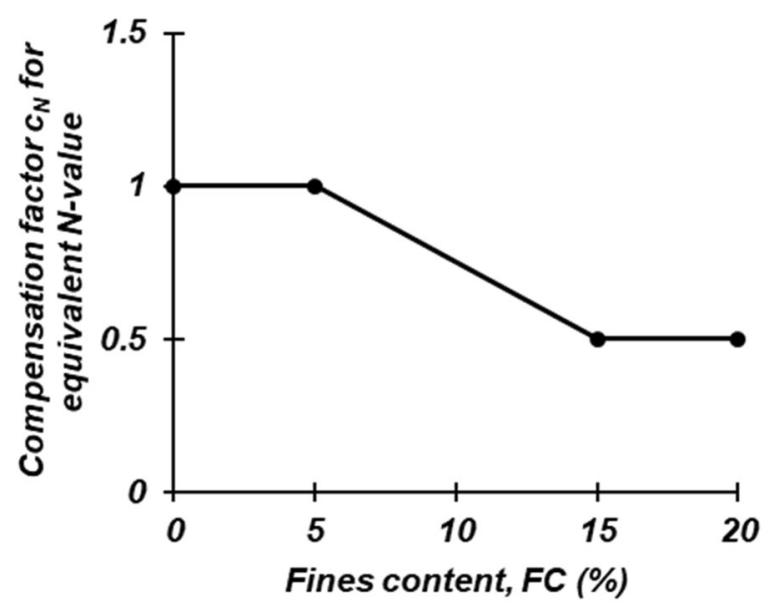

Fig. 11 Compensation Factor for Equivalent N-Value Corresponding to Fine Contents [9]

Table 6 Calculation details of liquefaction probability through OCDI [9] method for borehole B-25

\begin{tabular}{|c|c|c|c|c|c|c|c|c|c|c|c|c|c|}
\hline Depth $(m)$ & 1.5 & 3.0 & 4.5 & 6.0 & 7.5 & 9.0 & 10.5 & 12.0 & 13.5 & 15.0 & 16.5 & 18.0 & 19.5 \\
\hline \multicolumn{14}{|c|}{ Case $1: F C=5 \%, P l=5 \%$} \\
\hline$N_{65} / C_{N}$ & 3.587 & 3.205 & 3.980 & 5.755 & 4.287 & 3.928 & 3.597 & 2.377 & 1.246 & 1.049 & 0.037 & 1.493 & 0 \\
\hline$\alpha_{e q}$ & 171.1 & 220.5 & 242.2 & 252.4 & 257.3 & 257.8 & 254.2 & 246.8 & 236.4 & 224.0 & 211.4 & 199.4 & 189.3 \\
\hline Layer range & - & । & । & । & । & । & 1 & । & - & - & - & - & - \\
\hline \multicolumn{14}{|c|}{ Case $2: F C=15 \%, P I=10 \%$} \\
\hline$N_{65} / C_{N}$ & 7.173 & 6.410 & 7.961 & 11.51 & 8.573 & 7.856 & 7.195 & 4.754 & 2.493 & 2.097 & 0.074 & 2.985 & 0 \\
\hline$N+\Delta N$ & 11.59 & 11.20 & 11.98 & 13.75 & 12.29 & 11.93 & 11.60 & 10.38 & 9.246 & 9.049 & 8.037 & 9.493 & 8.000 \\
\hline$\alpha_{e q}$ & 171.1 & 220.5 & 242.2 & 252.4 & 257.3 & 257.8 & 254.2 & 246.8 & 236.4 & 224.0 & 211.4 & 199.4 & 189.3 \\
\hline Layer range & - & $\|$ & $\|$ & $\|$ & $\|$ & $\|$ & $\|$ & $\|$ & - & - & - & - & - \\
\hline \multicolumn{14}{|c|}{ Case $3: F C=35 \%, P I=20 \%$} \\
\hline$N+\Delta N$ & 15.59 & 15.20 & 15.98 & 17.75 & 16.29 & 15.93 & 15.60 & 14.38 & 13.25 & 13.05 & 12.04 & 13.49 & 12.00 \\
\hline$\alpha_{e q}$ & 171.1 & 220.5 & 242.2 & 2524 & 257.3 & 257.8 & 254.2 & 246.8 & 236.4 & 224.0 & 211.4 & 199.4 & 189.3 \\
\hline Layer range & - & III & III & III & III & III & III & III & - & - & - & - & - \\
\hline
\end{tabular}




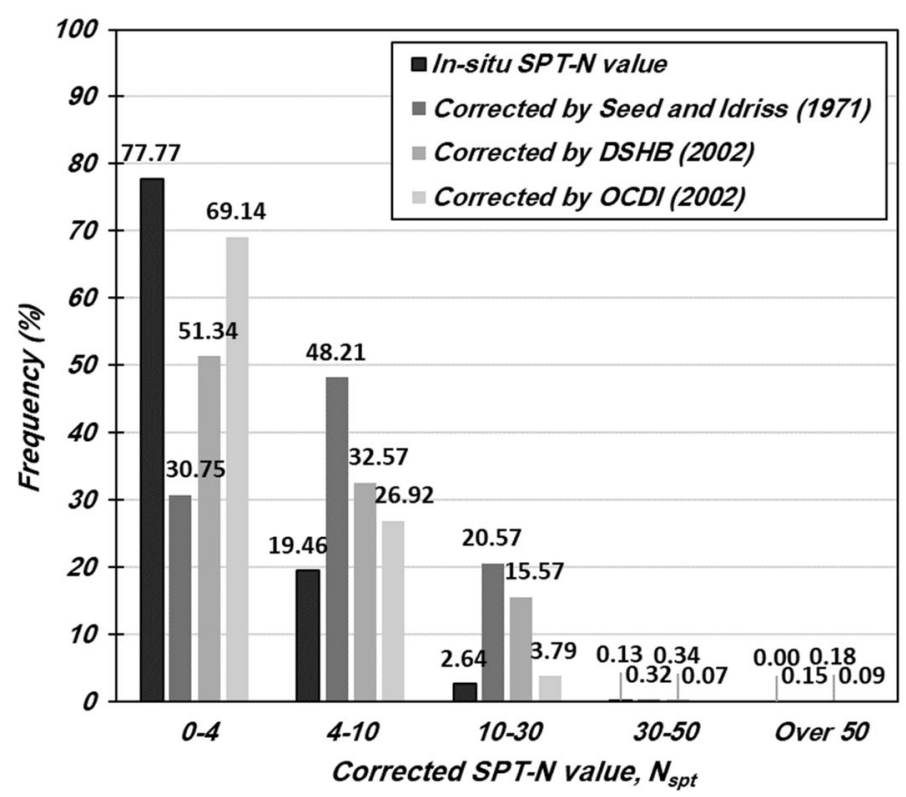

Fig. 12 Histogram of corrected SPT N-values by three methods

i. If $\mathrm{N}+\Delta \mathrm{N}$ falls within the range I in Fig. 10, the range I is used.

ii. If $\mathrm{N}+\Delta \mathrm{N}$ falls within the range II, the range II is used.

iii. If $\mathrm{N}+\Delta \mathrm{N}$ falls within the range III or IV and $(N)_{65} / 0.5$ is within range I, II or III, the range III is used.

iv. If $\mathrm{N}+\Delta \mathrm{N}$ falls within range III or IV and $(N)_{65} / 0.5$ is within range IV, the range IV is used.

The $\mathrm{I}_{\mathrm{p}}$ in Eq. (20) indicates the plasticity index.

Case C: If the plasticity index is 20 or greater, and the fines content is $15 \%$ or higher, the corrected equivalent $\mathrm{N}$-value should be set as $N+\Delta N$. The range should be determined according to the equivalent $\mathrm{N}$-value (after correction) and the equivalent acceleration.

Table 7 Parameters considered for reliability analysis

\begin{tabular}{lll}
\hline Parameters & Mean & COV \\
\hline$a_{\max } / g$ & 0.2 & 0.1 \\
$\sigma_{v}$ & $f(z)$ & 0 \\
$\sigma_{v}^{\prime}$ & $f(z)$ & 0 \\
$r_{d}$ & $f(z)$ & 0.05 \\
MSF & 1.0 & 0.05 \\
$\left(N_{1}\right)_{60 c s}$ & $f(z)$ & 0.15 \\
$k_{\sigma}$ & $f\left(\sigma_{v}^{\prime}\right)$ & 0 \\
\hline
\end{tabular}


Table 8 Calculation details of liquefaction probability through Jha and Suzuki [15] method for borehole B-25

\begin{tabular}{|c|c|c|c|c|c|c|c|c|c|c|c|c|c|}
\hline Depth $(m)$ & 1.5 & 3.0 & 4.5 & 6.0 & 7.5 & 9.0 & 10.5 & 12.0 & 13.5 & 15.0 & 16.5 & 18.0 & 19.5 \\
\hline \multicolumn{14}{|c|}{ Case $1: F C=5 \%, P I=5 \%$} \\
\hline FS & - & 0.271 & 0.289 & 0.349 & 0.283 & 0.271 & 0.265 & 0.237 & - & - & - & - & - \\
\hline$\beta^{\prime}$ & - & -2.84 & -2.44 & -1.85 & -2.42 & -2.56 & -2.65 & -3.15 & - & - & - & - & - \\
\hline$\Phi\left(\beta^{\prime}\right)$ & - & 0.002 & 0.007 & 0.031 & 0.008 & 0.005 & 0.004 & 0.000 & - & - & - & - & - \\
\hline$P(L)$ & - & 0.997 & 0.993 & 0.969 & 0.992 & 0.995 & 0.996 & 0.999 & - & - & - & - & - \\
\hline \multicolumn{14}{|c|}{ Case 2: $F C=15 \%, P I=10 \%$} \\
\hline FS & - & 0.356 & 0.376 & 0.443 & 0.367 & 0.353 & 0.347 & 0.313 & - & - & - & - & - \\
\hline$\beta^{\prime}$ & - & -1.69 & -1.54 & -1.30 & -1.55 & -1.61 & -1.65 & -1.87 & - & - & - & - & - \\
\hline$\Phi\left(\beta^{\prime}\right)$ & - & 0.046 & 0.062 & 0.097 & 0.060 & 0.053 & 0.050 & 0.031 & - & - & - & - & - \\
\hline$P(L)$ & - & 0.954 & 0.938 & 0.903 & 0.940 & 0.947 & 0.950 & 0.970 & - & - & - & - & - \\
\hline \multicolumn{14}{|c|}{ Case 3: $F C=35 \%, P I=20 \%$} \\
\hline FS & - & 0.467 & 0.490 & 0.573 & 0.477 & 0.459 & 0.452 & 0.410 & - & - & - & - & - \\
\hline$\beta^{\prime}$ & - & -1.24 & -1.18 & -1.06 & -1.21 & -1.24 & -1.26 & -1.37 & - & - & - & - & - \\
\hline$\Phi\left(\beta^{\prime}\right)$ & - & 0.108 & 0.118 & 0.145 & 0.114 & 0.107 & 0.104 & 0.085 & - & - & - & - & - \\
\hline$P(L)$ & - & 0.892 & 0.882 & 0.855 & 0.886 & 0.893 & 0.896 & 0.915 & - & - & - & - & $-n$ \\
\hline
\end{tabular}

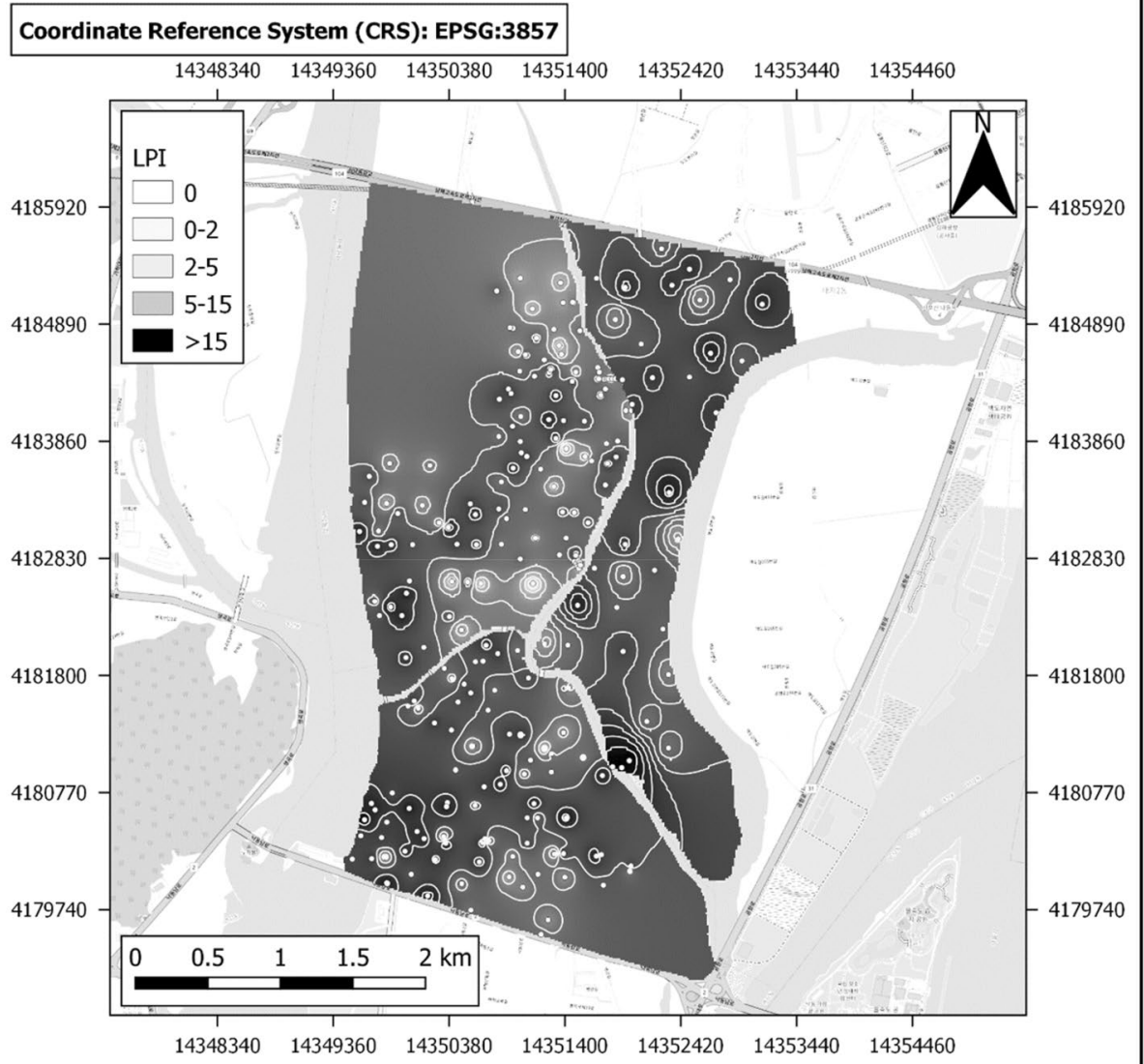

Fig. 13 Liquefaction hazard map based on Seed and Idriss [1] method for case 1 


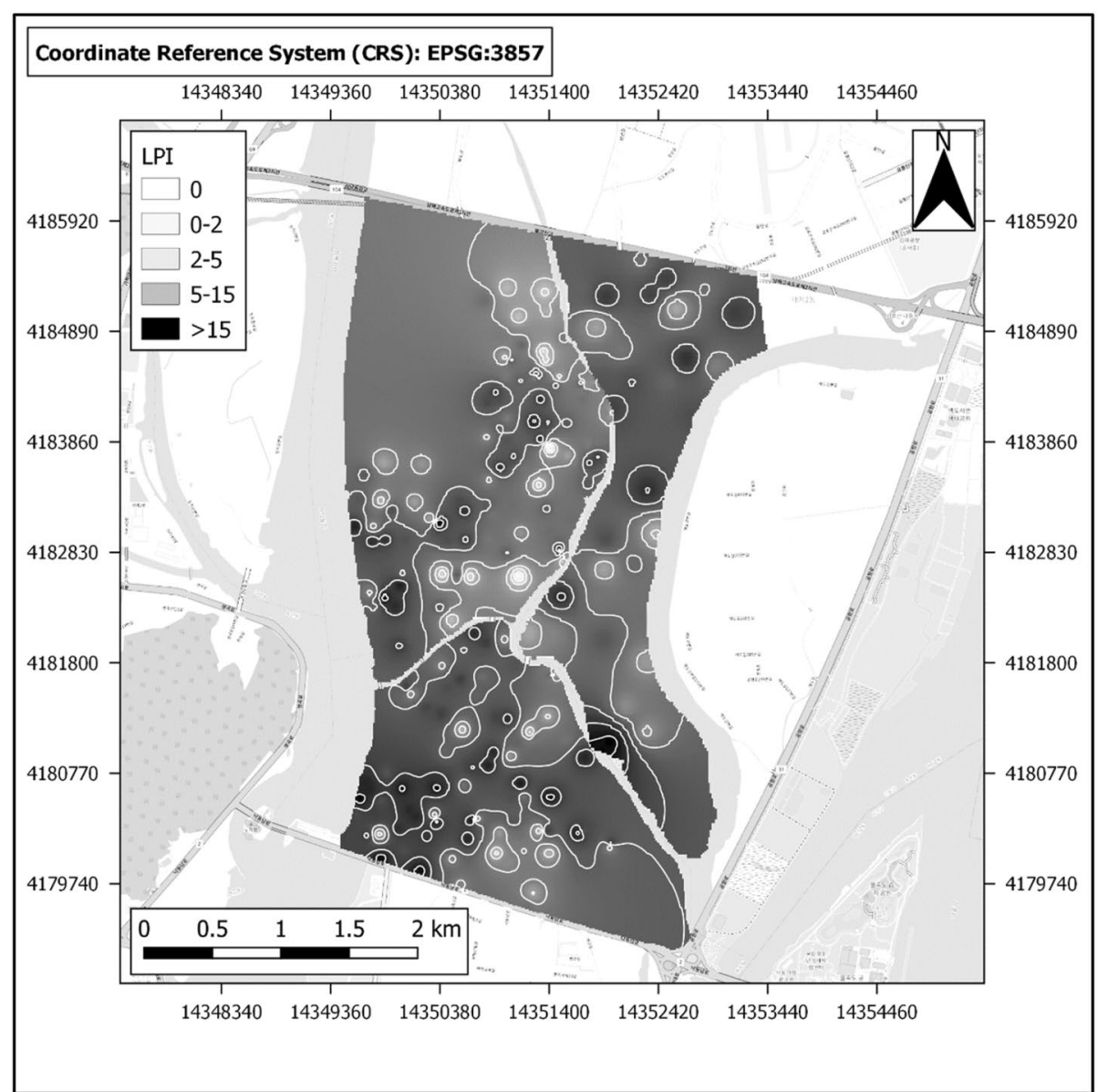

Fig. 14 Liquefaction hazard map based on Seed and Idriss [1] method for case 2

The result of liquefaction prediction through the OCDI [9] method for three cases for borehole B-25 is tabulated in Table 6.

In order to compare the calculation of corrected SPT N-values through three above mentioned methods $[1,8,9]$ for three cases, the histogram of them is shown in Fig. 12. From this figure and Fig. 6, which shows the in situ SPT N-value records, it is found that the correction through Seed and Idriss [1] method considers more change in the in situ counted SPT N-values, since about 31\% of corrected SPT N-values lie in the range zero to 4.0; while this was been over 78\%. Then, DSHB [8] and OCDI [9] methods have the more change in the in situ counted SPT N-values, respectively.

\section{Reliability evaluation of liquefaction probability}

Jha and Suzuki [15] defined a reliability based design safety factor which considers uncertainties in model parameters. Based on this approach, the susceptibility of soil liquefaction is defined in terms of probability of liquefaction. The susceptibility for liquefaction in terms of probability of liquefaction (PL) is obtained from the reliability index $\beta^{\prime}$ by Eq. (19): 


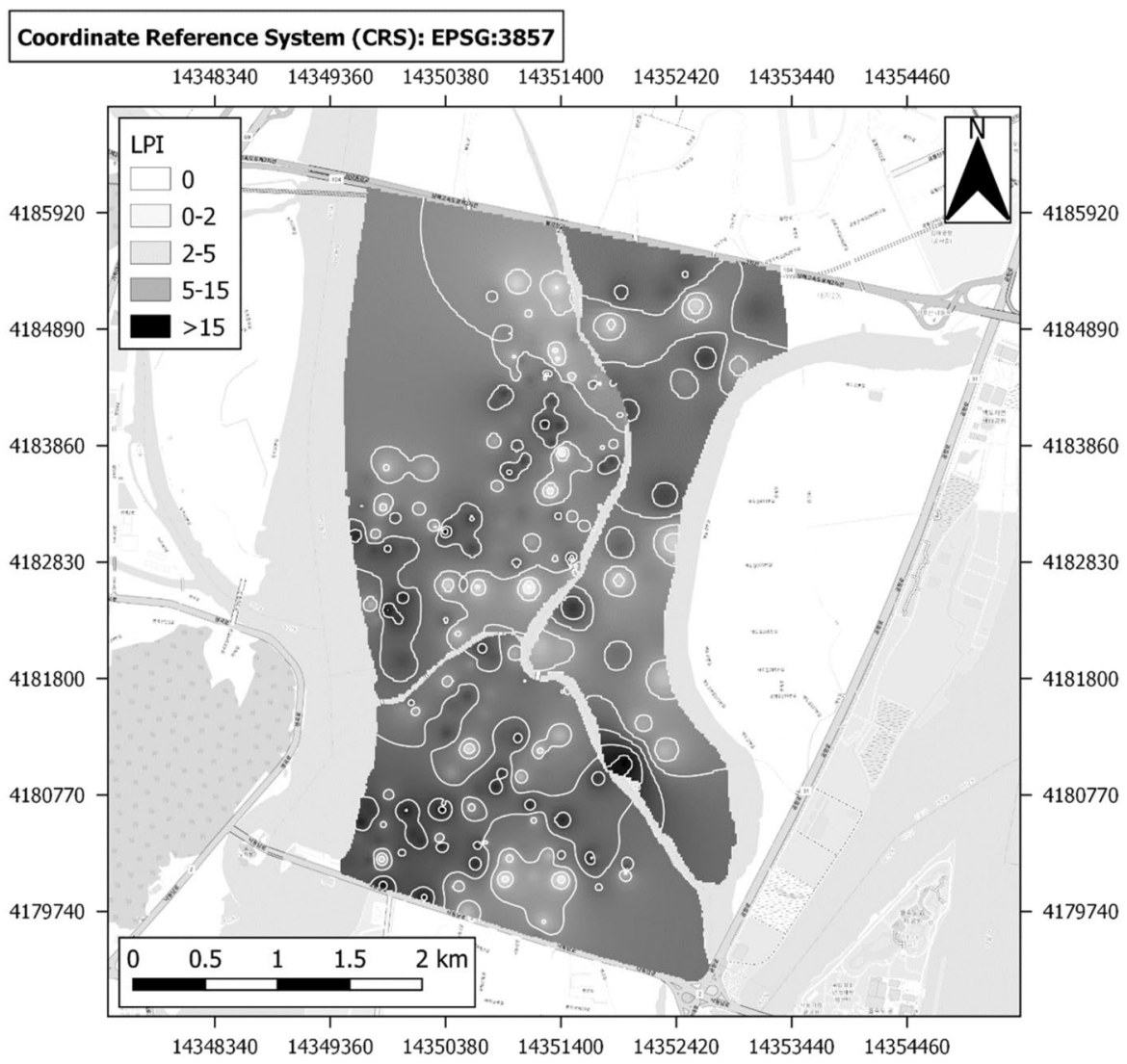

Fig. 15 Liquefaction hazard map based on Seed and Idriss [1] method for case 3

$$
P_{L}=1-\Phi\left(\beta^{\prime}\right)
$$

where $\Phi($.$) is the standard normal cumulative probability. The reliability index \beta^{\prime}$ can be expressed based on margin of safety approach. Assuming that CSR and CRR follows normal probability distribution, $\beta^{\prime}$ is defined as Eq. (20) [12]:

$$
\beta_{L N}^{\prime}=\frac{\ln \left[F S \sqrt{\frac{V_{C S R_{7,5, \sigma}+1}^{V_{C R R_{7}}^{2}+1}}{2}}\right]}{\sqrt{\ln \left[\left(V_{C S R_{7,5, \sigma}}^{2}+1\right)\left(V_{C R R_{7.5}}^{2}+1\right)\right]}}
$$

where the, COV (i.e. the ratio of standard deviation to mean) of $\mathrm{CSR}_{7.5 . \sigma}$ and $\mathrm{CRR}_{7.5}$ could be determined by first order second moment (FOSM) method. The FOSM method 


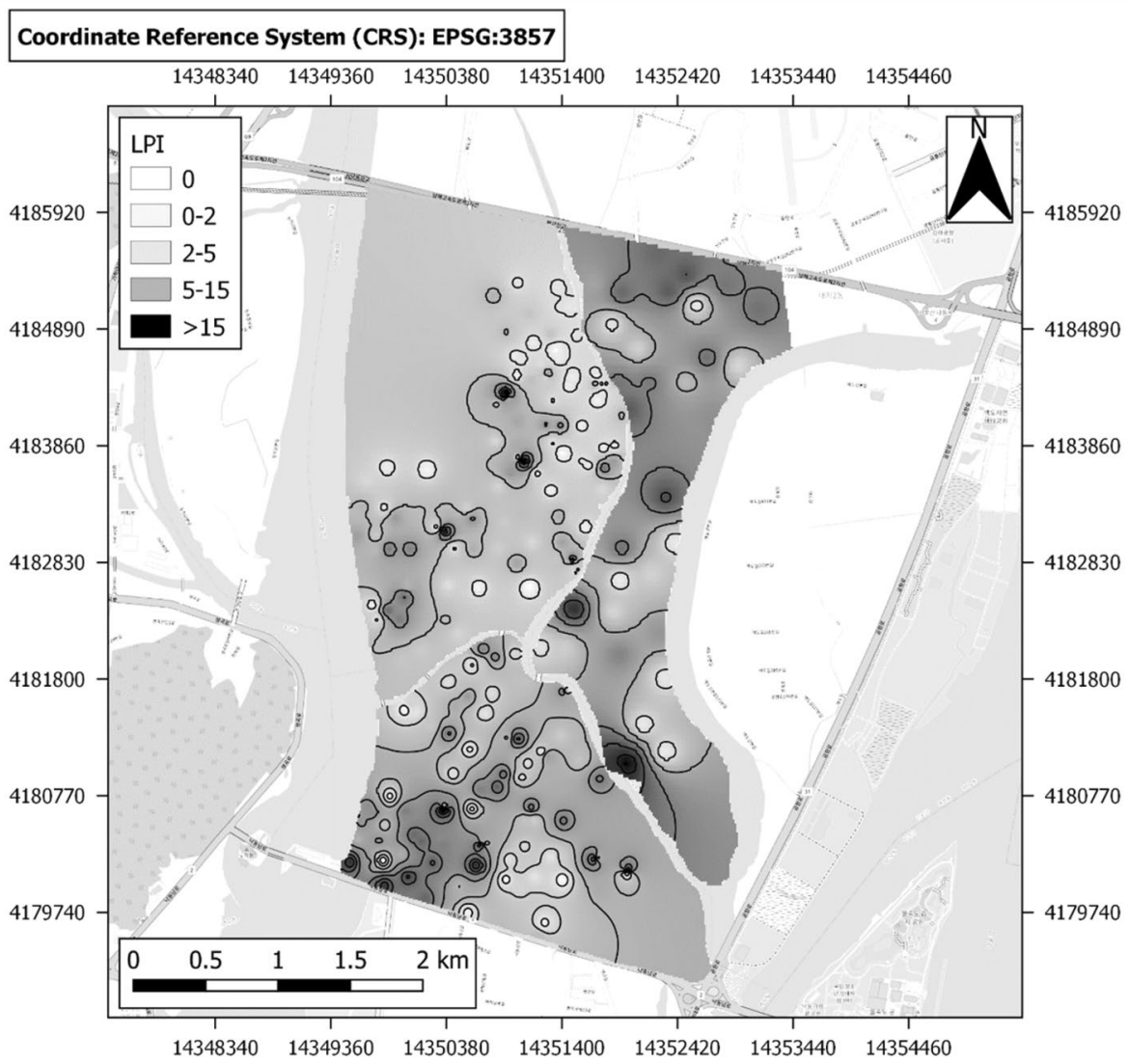

Fig. 16 Liquefaction hazard map based on DSHB [8] method for case 1

describes random variables using only their mean and standard deviation. Using the FOSM method, the COV of $\mathrm{CSR}_{7.5, \sigma}$ can be calculated as Eq. (21):

$$
V_{C S R_{7.5, \sigma}}^{2}=V_{a_{\max }}^{2}+V_{\sigma_{v}}^{2}+V_{\sigma_{v}^{\prime}}^{2}+V_{\gamma_{d}}^{2}+V_{M S F}^{2}+V_{k_{\sigma}}^{2}-2 \rho_{\sigma_{v} \sigma_{v}^{\prime}} V_{\sigma_{v}^{\prime}} V_{\sigma_{v}}
$$

where $\mathrm{V}$ represents the $\mathrm{COV}$ and $\rho_{\sigma_{v} \sigma_{v}^{\prime}}$ denotes the correlation coefficient between total and effective stress. Since $\sigma_{v} . \sigma_{v}^{\prime}$ and $k_{\sigma}$ are computed from bore log and in situ test data, they can be treated as deterministic values. The uncertainty in the $\operatorname{CSR}_{7.5 . \sigma}$ is mainly influenced by the uncertainty in predicting the peak ground acceleration, $\mathrm{a}_{\max }, \mathrm{MSF}$, and $\gamma_{\mathrm{d}}$. The $\mathrm{a}_{\max }$ is predicted by the empirical acceleration attenuation law. It is mentioned by Jha and Suzuki [15] that the uncertainties in the liquefaction evaluation have been merged into the corrected SPT N-value $\left(\mathrm{N}_{1}\right)_{60}$. That means the COV value in $\left(\mathrm{N}_{1}\right)_{60}$ represents all sources of uncertainty. 


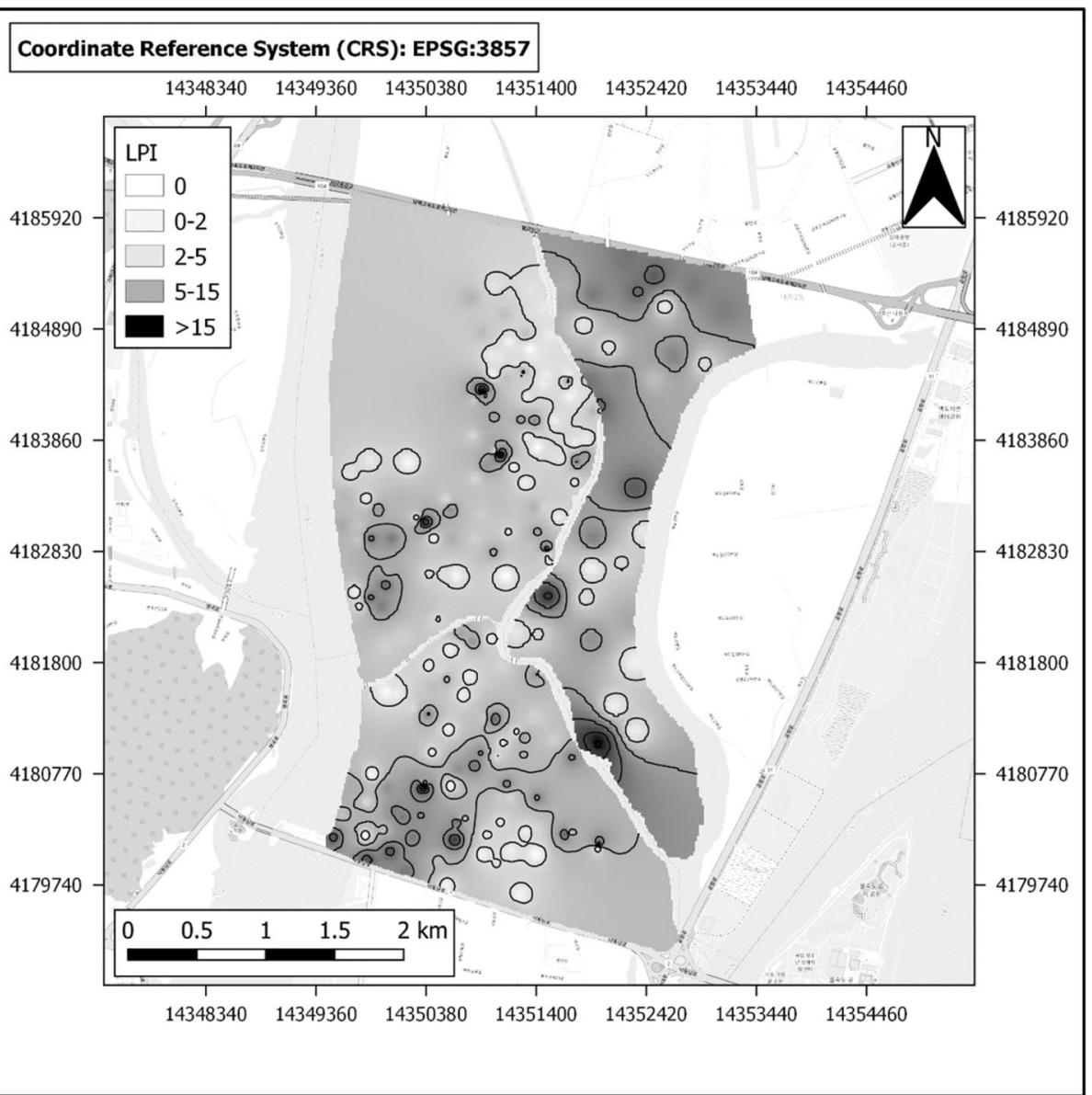

Fig. 17 Liquefaction hazard map based on DSHB [8] method for case 2

The COV of CRR 7.5 can be calculated through Eqs. (22) and (23):

$$
\begin{aligned}
& V_{C R R_{7.5}}=\frac{\Delta_{C R R_{7.5}}}{2 \mu_{C R R_{7.5}}} \\
& \Delta_{C R R_{7.5}}=C R R_{7.5}\left[\mu_{(N 1)_{60 c s}}+\sigma_{(N 1)_{60 c s}}\right]-C R R_{7.5}\left[\mu_{(N 1)_{60 c s}}-\sigma_{(N 1)_{60 c s}}\right]
\end{aligned}
$$

where $\mu_{\mathrm{CRR}_{7.5}}$ and $\mu_{(\mathrm{N} 1)_{60 \mathrm{cs}}}$ are the mean value of $\mathrm{CRR}_{7.5}$ and $\left(\mathrm{N}_{1}\right)_{60 \mathrm{cs}}$, respectively.

The COVs of the parameters are shown in Table 7.

Using the parameters from Table 7, the probability of liquefaction is evaluated as the reliability method and the results for three cases is tabulated in Table 8 for borehole B-25. 


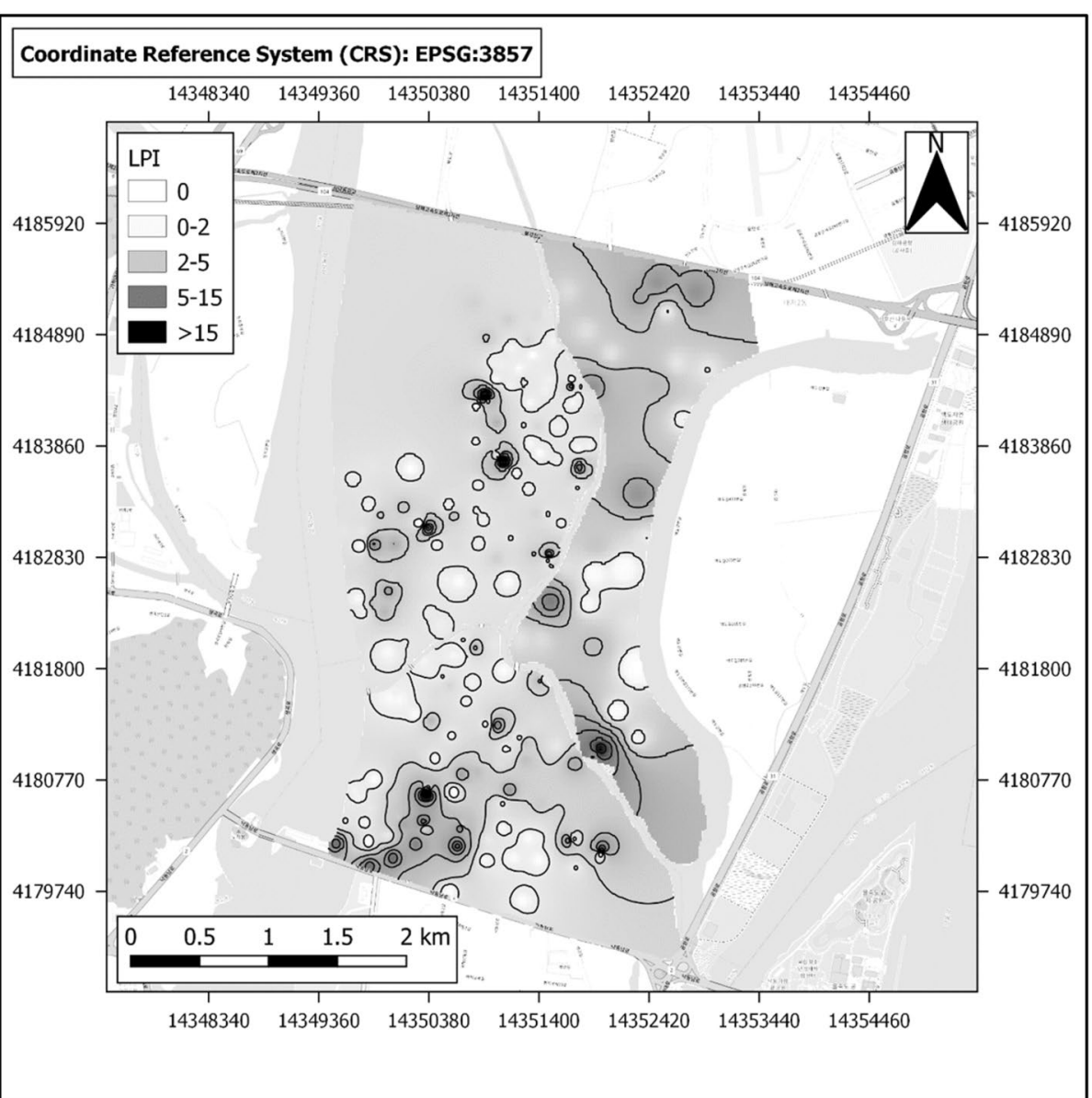

Fig. 18 Liquefaction hazard map based on DSHB [8] method for case 3

\section{Results and liquefaction hazard maps}

In order to show the distribution of the liquefaction risks in the Eco-Delta city, the liquefaction hazard maps are appropriate which provide the useful information for geotechnical engineers to check the susceptibility of the area against liquefaction and evaluating the seismic safety plans. There are variety of computer softwares which can facilitate mapping in geology fields. Among them, QGIS [21] program is used in the present study to produce liquefaction hazard maps using LPI values of 229 boreholes for three cases with different percent of fines content and plasticity indexes through the Inverse Distance Weighted (IDW) interpolation technique.

Liquefaction hazards are categorized based on the LPI values of the sites as LPI $=0$, $0<L P I \leq 2,2<L P I \leq 5,5<L P I \leq 15$ and LPI $>15$ according to the proposed range by Sonmez [7]. Figures 13,14 and 15 show the contour maps of the study area based on the FS of Seed and Idriss [1] method for case 1, 2 and 3, respectively. As it is expected, it 


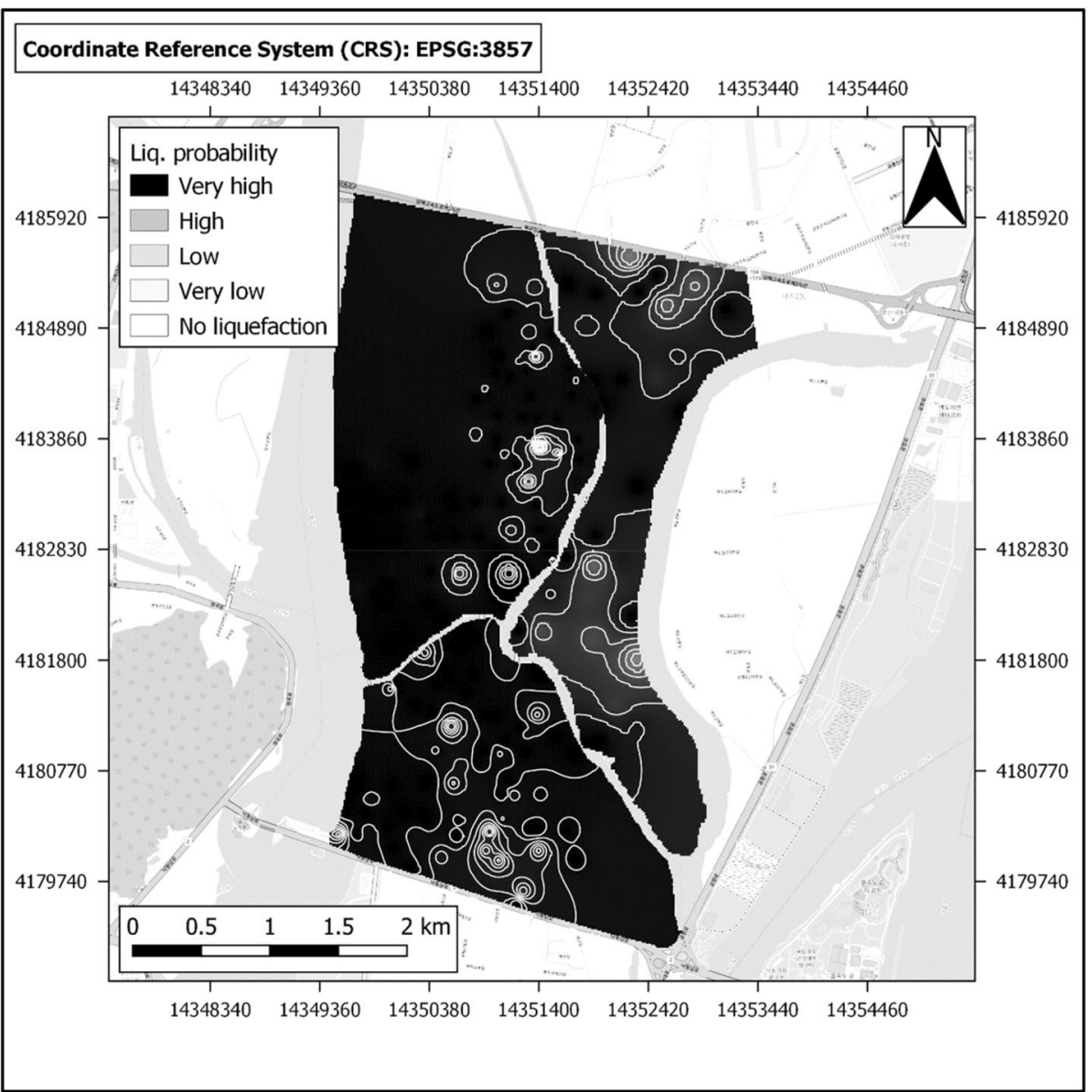

Fig. 19 Liquefaction hazard map based on OCDI [9] method for case 1

is seen that as the percent on fines content and plasticity index increases, the severity of liquefaction decreases for the sites.

The LPI contour maps of the study area based on the FS obtained from DSHB [8] method are shown in Figs. 16, 17 and 18 for case 1, 2 and 3, respectively. Similar to the maps by Seed and Idriss [1] method, it is seen that as the percent on fines content and plasticity index increases, the severity of liquefaction decreases. However, the result show that DSHB [8] method estimates less liquefaction susceptibility rather than Seed and Idriss [1] method. Moreover, the effect of fines content and plasticity index is found to be more in this method, since the prediction of liquefaction changes deviates more from case 1 to case 2 and from case 2 to case 3 .

The liquefaction probability hazard maps based on the OCDI [9] method are shown in Figs. 19, 20 and 21 for case 1, 2 and 3, respectively. The liquefaction probabilities are categorized as very low, low, high and very high based on the proposed range by OCDI 


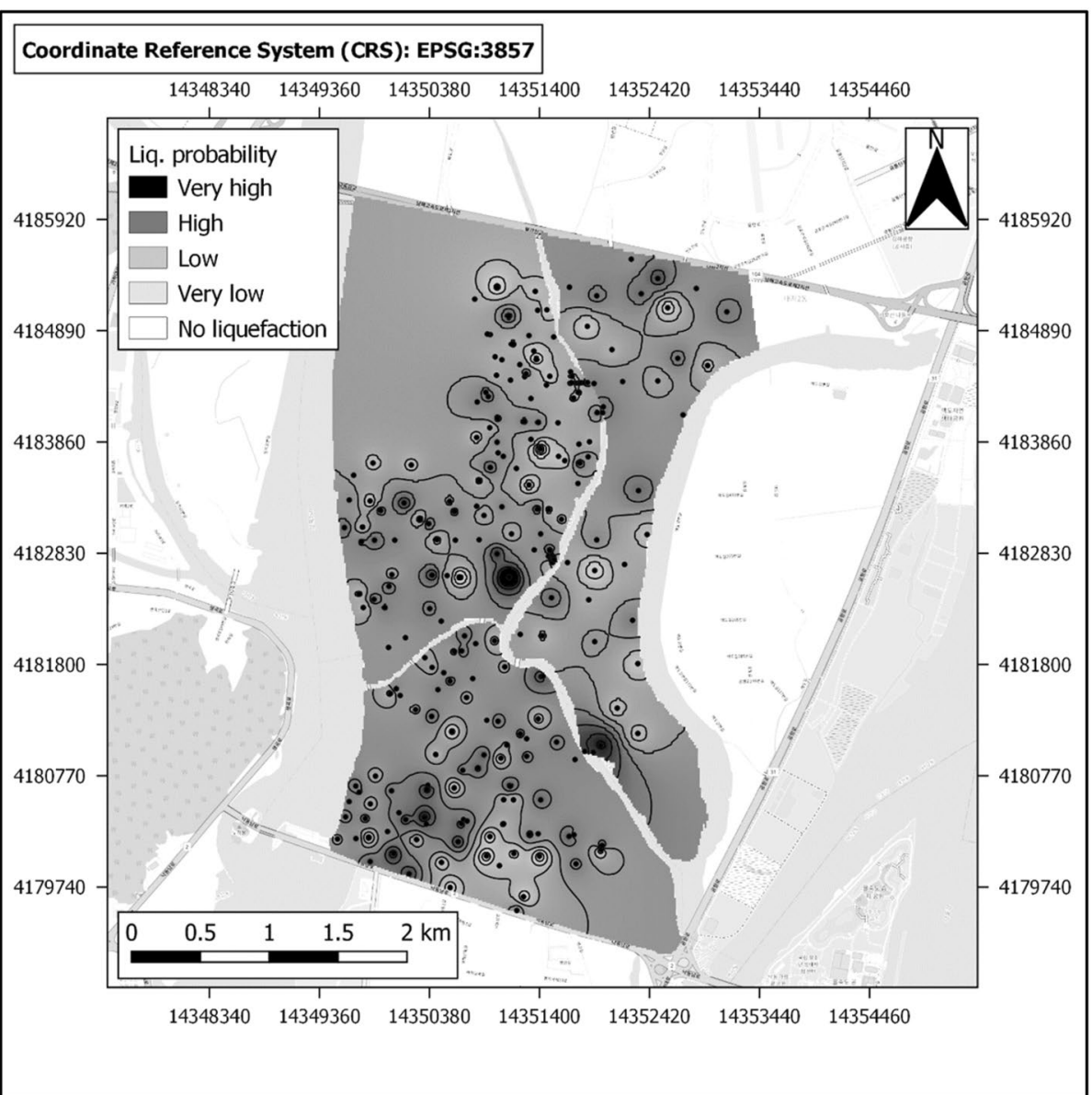

Fig. 20 Liquefaction hazard map based on OCDI [9] method for case 2

[9]. These figures show that the fines content have a significant effect on the liquefaction probability, since the severity of liquefaction dramatically changes from case 1 to case 2 and from case 2 to case 3 . It is seen that the probability of liquefaction is almost low for case 3 .

Finally, the liquefaction probability hazard maps according to the reliability method are plotted in Figs. 22, 23 and 24 for case 1, 2 and 3, respectively. Since in this approach some uncertainty factors are considered, the probability of liquefaction is estimated higher than the other methods. Assuming a threshold value of $25 \%$ for liquefaction probability, there is no site safe against liquefaction. Almost all sites show the very high probability of liquefaction in case 1 and it does not decrease to low probability of liquefaction even in case 3. 


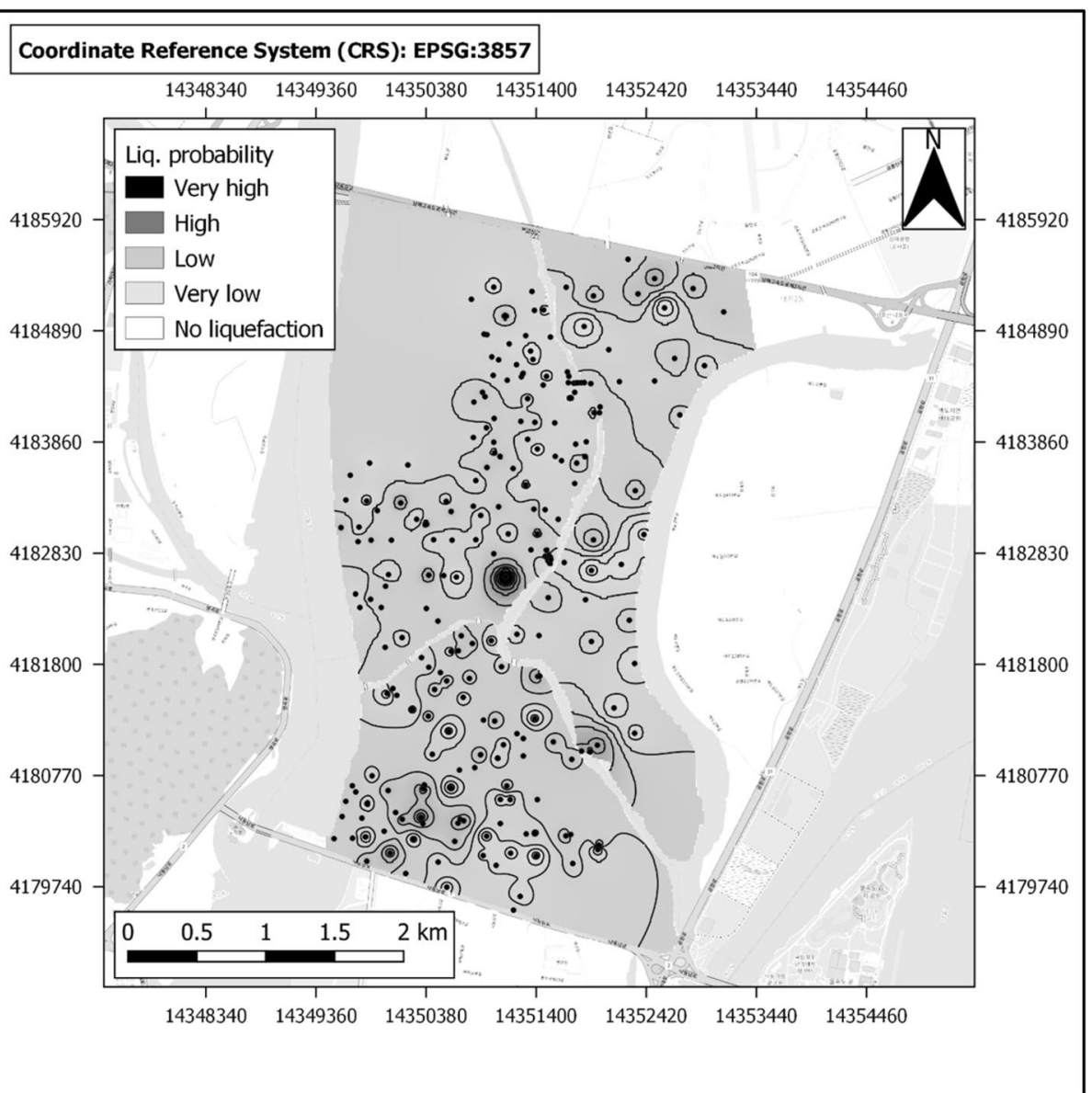

Fig. 21 Liquefaction hazard map based on OCDI [9] method for case 3

\section{Conclusions}

This study evaluates the SPT-based susceptibility of liquefaction in Eco-Delta city (Busan province) in South Korea. Data from 229 sites are collected and 2765 factors of safety against liquefaction are calculated. In order to investigate the effect of fines content on liquefaction susceptibility in the study area, three different cases are considered for fines content and plasticity index. The liquefaction probability is also investigated through deterministic and reliability approaches. The liquefaction hazard maps are generated for the area to predict the occurrence of liquefaction for the earthquakes of magnitude 7.5 with peak horizontal ground acceleration of $0.2 \mathrm{~g}$.

The results showed that increasing the percent of fines content from $5 \%$ to $35 \%$ causes increase in majority of FS from 0.6 to 1.0. Moreover, it leads to decrease in probability of liquefaction about $10 \%$. Since the GWT is very high in the study area, and because higher GWT increases the CSR by the ratio of total and effective vertical stress, so it 


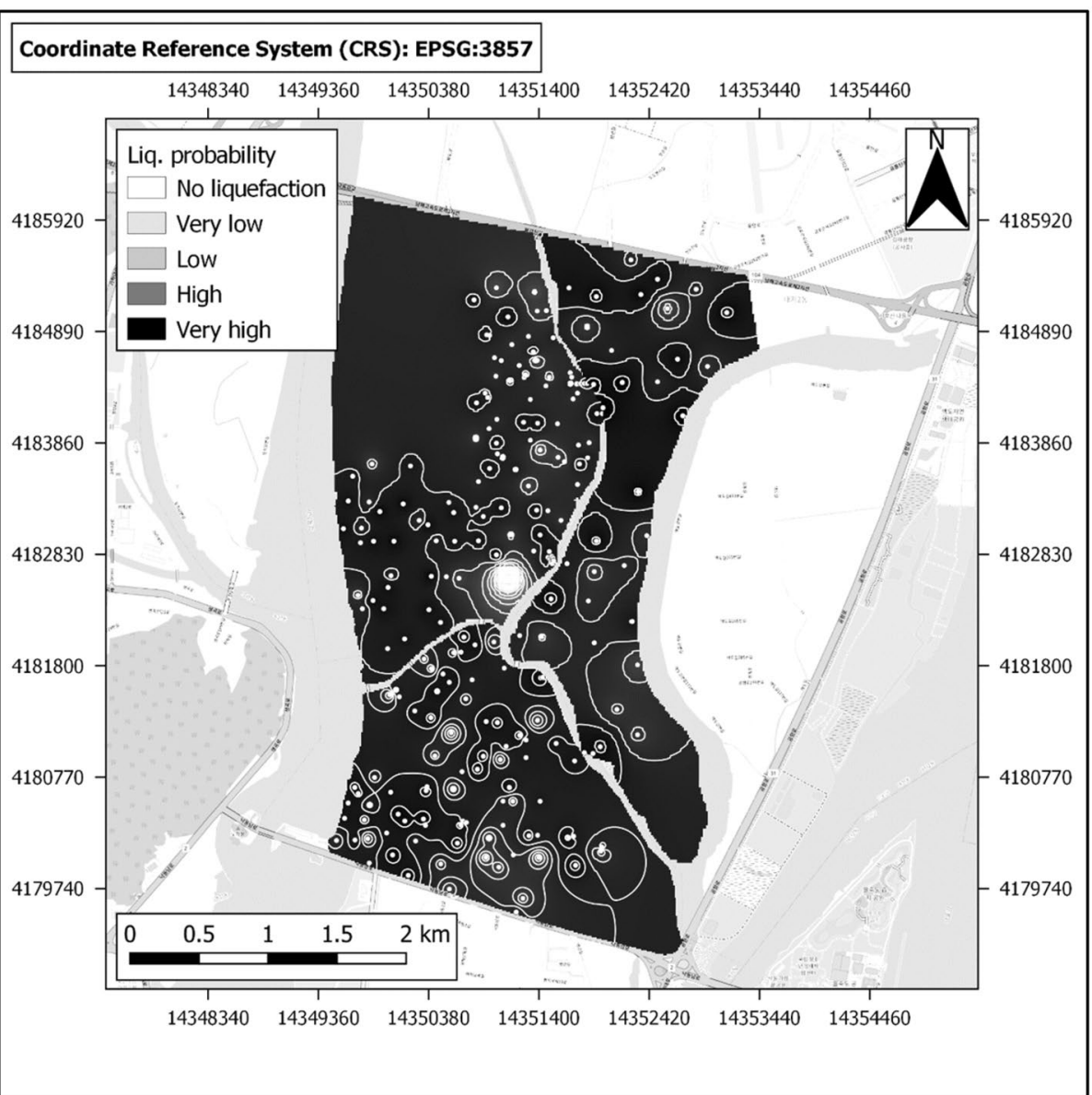

Fig. 22 Liquefaction hazard map based on reliability method for case 1

reduces FS against liquefaction and is heavily weighted in computing LPI, and thus, about $91 \%$ of the sites showed very high liquefaction susceptibility by LPI values over 15 . Moreover, it leads the sites to be unsafe against liquefaction; since among 687 sites, only one soil column is safe against liquefaction by the LPI less than 2. So the city is found to be highly vulnerable for liquefaction. Assuming a threshold value of $25 \%$ for liquefaction susceptibility, no site is safe against liquefaction through reliability approach. The hazard maps indicate that the susceptibility of liquefaction decreases by increasing the 


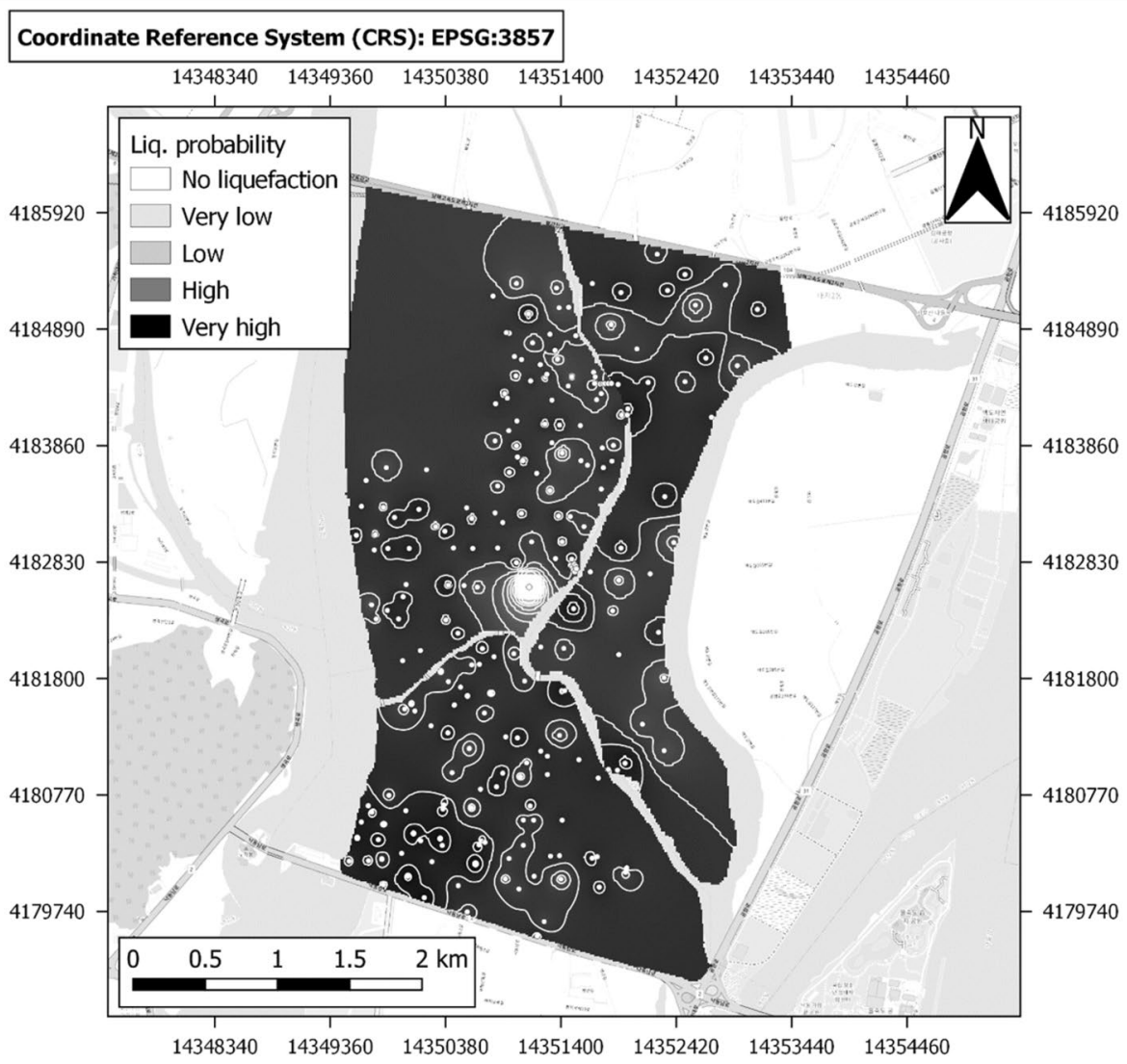

Fig. 23 Liquefaction hazard map based on reliability method for case 2

percent of fines content and plasticity index from case 1 to case 2 and from case 2 to case3, as it was expected. However, the changes were different for each approach. It is found that the OCDI approach showed more sensitivity (about 25\%) to different percentages of fines content and the predicted liquefaction risks significantly varied for each 


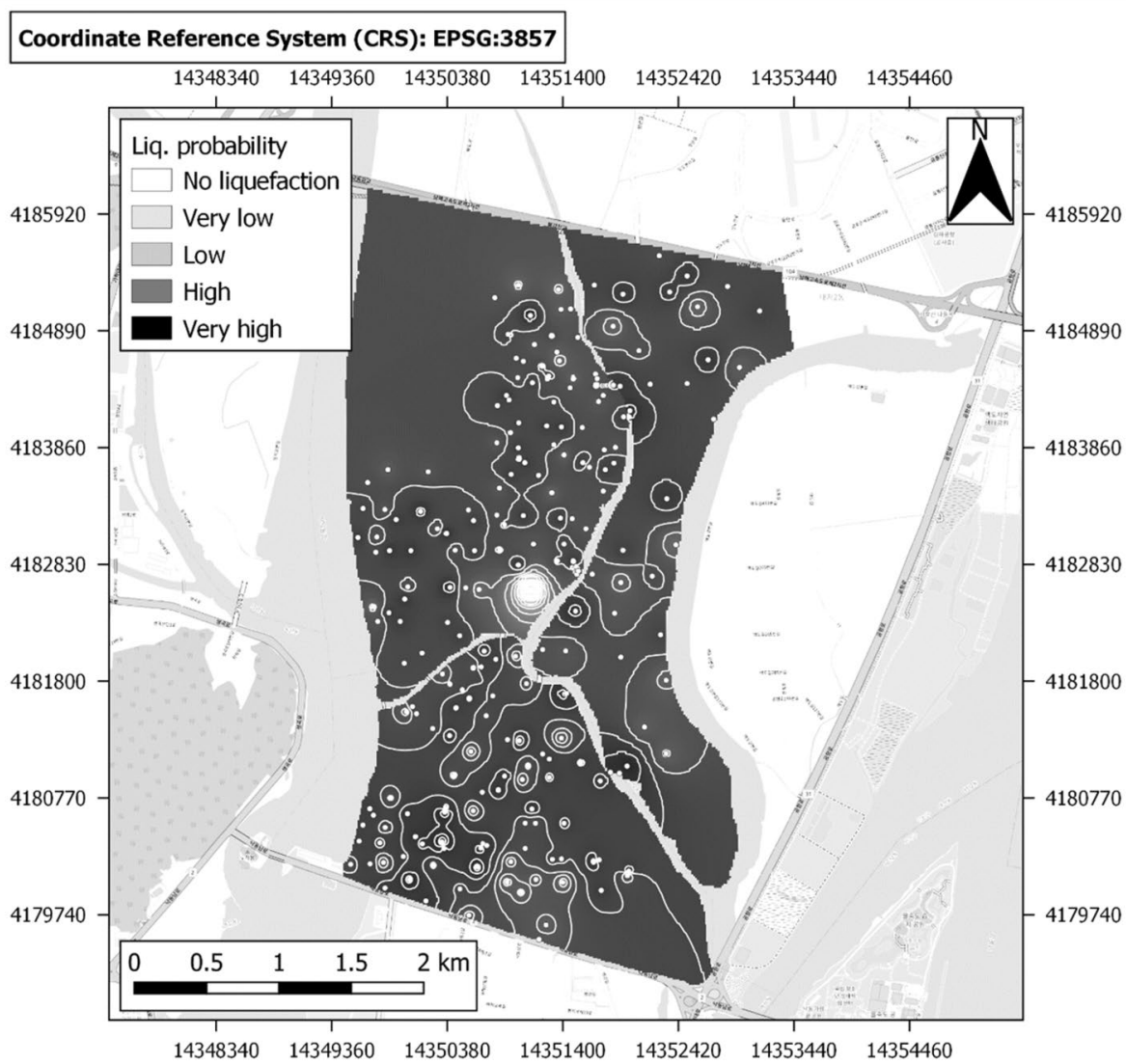

$\begin{array}{lllllll}14348340 & 14349360 & 14350380 & 14351400 & 14352420 & 14353440 & 14354460\end{array}$

Fig. 24 Liquefaction hazard map based on reliability method for case 3

case of fines content through this approach. In contrast, the reliability approach showed less sensitivity (about 5\%) to different percentages of fines content. The number of sites predicted to be liquefied by reliability approach are higher comparing to the deterministic approaches as well as the liquefaction severity.

\section{Abbreviations}

$a_{\text {max }}$ : Peak horizontal acceleration at ground surface; $C_{1}$ and $C_{2}$ : Correction factors for fines content; $C_{B}$ : Correction factor for borehole diameter; $\mathrm{C}_{\mathrm{E}}$ : Correction factor for hammer energy; $\mathrm{C}_{\mathrm{N}}$ : Correction factor for overburden pressure applied to SPT; $C_{R}$ : Correction factor for drilling rod length; $C_{S}$ : Correction factor for split spoon sampler without liners; $C_{w}$ : Modification factor on the earthquake ground motion; $C_{2 R}$ : Cyclic resistance ratio for $M_{w}=7.5$ earthquakes; $C S R$ : Cyclic stress ratio; f: Exponent estimated from site conditions used in calculation of $\mathrm{K}_{\sigma} ; \mathrm{FC}$ : Fines content; FS: Factor of safety; g: Acceleration of gravity; LPI: Liquefaction potential index; MSF: Magnitude scaling factor of earthquake; $\left(\mathrm{N}_{1}\right)_{60}$ : Corrected standard penetration resistance; $\left(\mathrm{N}_{1}\right)_{60 c s}:\left(\mathrm{N}_{1}\right)_{60}$ adjusted to equivalent clean-sand value; $\mathrm{N}_{65}$ : Equivalent $\mathrm{N}$-value; $\mathrm{N}_{\mathrm{a}}$ : Modified N-value regarding the DSHB method; $\mathrm{N}_{\mathrm{m}}$ : Measured standard penetration resistance; PL: Probability of liquefaction; PI: Plasticity index; $r_{d}$ : Stress reduction coefficient to account for flexibility in soil profile; $R_{L}$ : Cyclic triaxial shear resistance ratio; $\vee$ : Coefficient of variation for parameters in reliability method; $z$ : Depth below ground surface; $a_{e q}$ : Equivalent acceleration; $\alpha, \beta$ : Coefficients, that are functions of fines content; $\beta^{\prime}$ : Reliability index; $\gamma$ : Soil unit weight; $\mu$ : Mean value of parameters in reliability method; $\sigma_{\text {vo }}$ : Total overburden pressure; $\sigma_{\text {vo }}^{\prime}$ : Effective overburden pressure; $\Phi($.$) :$ Standard normal cumulative probability. 


\section{Acknowledgements}

This research was supported by the Basic Research Project (19-3413) of the Korea Institute of Geoscience and Mineral Resources (KIGAM) funded by the Ministry of Science and ICT of South Korea.

Authors' contributions

All authors read and approved the final manuscript.

\section{Competing interests}

The authors declare that they have no competing interests.

\section{Author details}

1 Department of Civil and Environmental Engineering, Korea Maritime and Ocean University, 727 Taejong-ro, Youngdo-Gu, Busan 49112, Republic of Korea. ${ }^{2}$ Korea Institute of Geoscience and Mineral Resources, Geo-Environmental Hazard Research Center, 124 Kwahak-ro, Yuseong-Gu, Daejeon 34132, Republic of Korea.

Received: 22 February 2020 Accepted: 15 July 2020

Published online: 03 September 2020

\section{References}

1. Seed HB, Idriss IM (1971). Simplified procedure for evaluating soil liquefaction potential, J. Geotech. Eng., ASCE 97; 1249-1273. http://refhub.elsvier.com/S0013-7952(17)31840-9//f0200

2. Youd T, Perkins DM (1987) Mapping of liquefaction severity index. J Geotech Eng ASCE 113(11):1374-1392. https://doi. org/10.1061/(ASCE)0733-9410(1987)113:11(1374)

3. Youd TL, Idriss IM, Andrus RD, Arango I, Castro G, Christian JT, Dobry R, Finn WL, Harder LF Jr, Hynes ME, Ishihara K (2001) Liquefaction resistance of soils: summary report from the 1996 NCEER 14 and 1998 NCEER/NSF workshops on evaluation of liquefaction resistance of soils. J Geotechn Geoenviron Eng 127(10):817-833. https://doi.org/10.1061/ (ASCE) 1090-0241(2001)127:4(297)

4. Seed HB, Tokimatsu K, Harder LF, Chung RM (1985) Influence of SPT procedures in soil liquefaction resistance evaluations. J Geotech Eng 111(12):1425-1445. https://doi.org/10.1061/(ASCE)0733-9410(1985)111:12(1425)

5. T. Iwasaki, F. Tatsuoka, K.I. Tokida, S. Yasuda. (1978). A practical method for assessing soil liquefaction potential based on case studies at various sites in Japan, Proc. of $2^{\text {nd }}$ International Conference on Microzonation, San Francisco, pp. 885-896. http://refhub.elsvier.com/S0013-7952(15)00023-X/rf0300

6. T. Iwasaki, K. Tokida, F. Tatsuoka, S. Watanabe, S. Yasuda, H. Sato. (1982). Microzonation for soil liquefaction potential using simplified methods, Proceedings of the $3^{\text {rd }}$ International Earthquake Microzonation Conference, Seattle, pp. 1319-1330. http://refhub.elsvier.com/S0013-7952(15)00023-X/rf0305

7. Sonmez H (2003) Modification of the liquefaction potential index and liquefaction susceptibility mapping for a liquefaction-prone area (Inegol, Turkey). Environ Geol 44(7):862-871. https://doi.org/10.1007/s00254-003-0831-0

8. Japan Road Association. (2002). Design Specifications for Highway Bridges, Part V: Seismic Design, Japan. http://iisee .kenken.go.jp/worldlist/29_Japan/29_Japan_2_HighwayBridge_Code_2002_01.pdf

9. Overseas Coastal Area Development Institute of Japan. (2002). Technical standards and commentaries for port and harbor facilities, Japan. http://ocdi.or.jp/tec_st/tec_pdf/tech_271_311.pdf\#page=12

10. Liao SSC, Veneziano D, Whitman RV (1988) Regression models for evaluating liquefaction probability. J Geotech Eng 114(4):389-411. https://doi.org/10.1061/(ASCE)0733-9410(1988)114:4(389)

11. Juang CH, Yuan H, Lee DH, Lin PS (2003) A simplified CPT-based method for evaluating liquefaction potential of soils. J Geotech Geoenviron Eng 129(1):66-80. https://doi.org/10.1061/(ASCE)1090-0241(2003)129:1(66)

12. Hwang JH, Yang CW, Juang DS (2004) A practical reliability-based method for assessing soil liquefaction potential. Soil Dyn Earthq Eng 24:761-770. https://doi.org/10.1016/j.soildyn.2004.06.008

13. Juang $\mathrm{CH}$, Chen CJ, Jiang T, Andrus RD (2000) Risk-based liquefaction potential evaluation using standard penetration tests. Can Geotech J 37:1195-1208. https://doi.org/10.1139/t00-064

14. Cetin KO, Seed RB, Kiureghian AD, Tokimatsu K, Harder LF Jr, Kayen RE, Moss RES (2004) Standard penetration testbased probabilistic and deterministic assessment of seismic soil liquefaction potential. J Geotech Geoenviron Eng 130(12):1314-1340. https://doi.org/10.1061/(ASCE)1090-0241(2004)130:12(1314)

15. Jha SK, Suzuki K (2009) Liquefaction potential index considering parameter uncertainties. Eng Geol 107:55-60. https:// doi.org/10.1016/j.enggeo.2009.03.012

16. H.J. Lim. (2018). Seismic hazard assessment using geotechnical characteristics and geographic information system in Busan city, Master of Science Thesis. Busan National University, Busan. http://dcollection.pusan.ac.kr/common/orgVi ew/000000133364 (In Korean with English abstract)

17. Chough SK, Sohn YK (2010) Tectonic and sedimentary evolution of a cretaceous continental arc-backarc system in the Korean peninsula: new view. Korea Earth Sci Rev 101:225-249. https://doi.org/10.1016/j.earscirev.2010.05.004 
18. K. Terzaghi, R.B. Peck, G. Mesri. (1996). Soil mechanics in engineering practice, Third ed., New York, Wiley. https://geoer apg09.files.wordpress.com/2017/06/karl-terzaghi-ralph-b-peck-gholamreza-mesri-soil-mechanics-in-engineering-pract ice-wiley-interscience-1996.pdf

19. Seed HB, Idriss IM (1982). Ground motions and soil liquefaction during earthquakes, Earthquake Engineering Research Institute, University of California, Berkeley. http://refhub.elsvier.com/S0013-7952(17)31840-9/rf0205

20. J.B. Park, J.H. Ahn, H. Choi, G.S. Kim, G.C. Kang. (2018). Application of existing distance attenuation relationships using PGAs recorded during earthquakes, Journal of the Korean Society of Hazard Mitigation 18 (6) 149-159. . j-kosham.or.kr/ upload/pdf/KOSHAM-2018-18-6-149.pdf (in Korean with English abstract)

21. QGIS Development Team. (2018). QGIS Geographic Information System, Open Source Geospatial Foundation. http://qgis.org

\section{Publisher's Note}

Springer Nature remains neutral with regard to jurisdictional claims in published maps and institutional affiliations.

Submit your manuscript to a SpringerOpen ${ }^{\circ}$ journal and benefit from:

- Convenient online submission

- Rigorous peer review

- Open access: articles freely available online

- High visibility within the field

- Retaining the copyright to your article

Submit your next manuscript at $\boldsymbol{\nabla}$ springeropen.com 